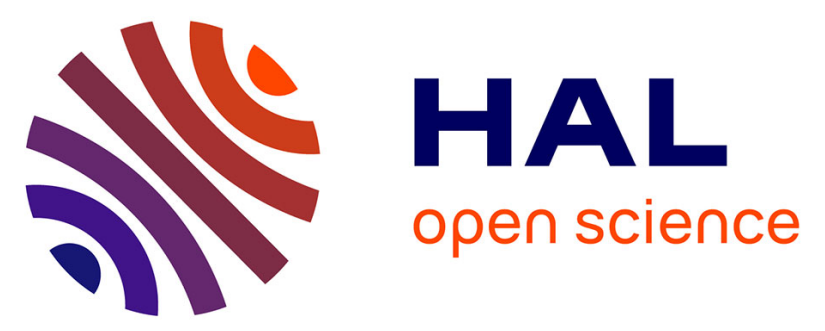

\title{
Pentagonal Bipyramidal Ln(III) Complexes Containing an Axial Phosphine Oxide Ligand: Field-induced Single-ion Magnetism Behavior of the Dy(III) Analogues
} Pankaj Kalita, Naushad Ahmed, Arun Kumar Bar, Sourav Dey, Anukul Jana, Gopalan Rajaraman, Jean-Pascal Sutter, Vadapalli Chandrasekhar

\section{To cite this version:}

Pankaj Kalita, Naushad Ahmed, Arun Kumar Bar, Sourav Dey, Anukul Jana, et al.. Pentagonal Bipyramidal Ln(III) Complexes Containing an Axial Phosphine Oxide Ligand: Field-induced Singleion Magnetism Behavior of the Dy(III) Analogues. Inorganic Chemistry, 2020, 59 (9), pp.6603-6612. 10.1021/acs.inorgchem.0c00751 . hal-02565216

\author{
HAL Id: hal-02565216 \\ https://hal.science/hal-02565216
}

Submitted on 10 Nov 2020

HAL is a multi-disciplinary open access archive for the deposit and dissemination of scientific research documents, whether they are published or not. The documents may come from teaching and research institutions in France or abroad, or from public or private research centers.
L'archive ouverte pluridisciplinaire HAL, est destinée au dépôt et à la diffusion de documents scientifiques de niveau recherche, publiés ou non, émanant des établissements d'enseignement et de recherche français ou étrangers, des laboratoires publics ou privés. 


\section{Pentagonal Bipyramidal Ln(III) Complexes Containing an Axial Phosphine Oxide}

\section{Ligand: Field-induced Single-ion Magnetism Behavior of the Dy(III) Analogues}

Pankaj Kalita, ${ }^{a, b}$ Naushad Ahmed, ${ }^{\ddagger b}$ Arun Kumar Bar, ${ }^{a}$ Sourav Dey, ${ }^{\ddagger c}$ Anukul Jana, ${ }^{b}$ Gopalan Rajaraman $^{* c}$, Jean-Pascal Sutter $*^{d}$ and Vadapalli Chandrasekhar $*^{b, e}$

${ }^{\text {a }}$ School of Chemical Sciences, National Institute of Science Education and Research, HBNI, Bhubaneswar -752050, India.

${ }^{\mathrm{b}}$ Tata Institute of Fundamental Research Hyderabad, Gopanpally, Hyderabad-500107, India.

${ }^{c}$ Departrment of Chemistry, Indian Institute of Technology Bombay, Mumbai-400 076, India

d Laboratoire de Chimie de Coordination du CNRS (LCC-CNRS), Université de Toulouse, CNRS, Toulouse, France.

${ }^{\mathrm{e}}$ Department of Chemistry, IIT Kanpur, Kanpur 208016, India.

*vc@tifrh.res.in; vc@iitk.ac.in; sutter@lcc-toulouse.fr; rajaraman@chem.iitb.ac.in

${ }^{*}$ Authors contributed equally in this manuscript

\section{Abstract}

A series of neutral homologous complexes $\left[(\mathrm{L}) \mathrm{Ln}\left(\mathrm{Cy}_{3} \mathrm{PO}\right) \mathrm{Cl}\right]\{$ where $\mathrm{Ln}=\mathrm{Gd}(\mathbf{1}), \mathrm{Tb}(\mathbf{2})$, Dy (3) and $\mathrm{Er}$ (5) $\}$ and $\left[(\mathrm{L}) \mathrm{Dy}\left(\mathrm{Ph}_{3} \mathrm{PO}\right) \mathrm{Cl}\right]$ (4) $\left[\mathrm{H}_{2} \mathrm{~L}=\right.$ 2,6-diacetylpyridine bisbenzoylhydrazone] have been isolated. In these complexes, the central lanthanide ion possesses a pentagonal bipyramidal (PBP) geometry with an overall pseudo $\mathrm{D}_{5 \mathrm{~h}}$ symmetry. The coordination environment around the lanthanide ion comprises of three nitrogen and two oxygen donors in an equatorial plane. The axial positions are taken up by a phosphine oxide (O donor) and a chloride ion. Among these compounds, the Dy(III) (3 and 4) analogues were found to be field-induced single-ion magnets. 


\section{Introduction}

There has been a significant renaissance in the chemistry of the rare earth elements because of their applications in catalysis ${ }^{1}$, photophysical properties ${ }^{2}$ and in magnetic materials ${ }^{3}$. In recent years lanthanide- ${ }^{4}$ and some actinide complexes ${ }^{5}$ are finding increasing utility as molecular magnets (single-molecule- and single-ion magnets; SMMs and SIMs). These molecular systems, once magnetized, retain their magnetization even after the removal of the external magnetic field and are characterized by a slow reversal of magnetization below certain temperatures. ${ }^{6}$ This is because in SMMs, on application of a magnetic field, a doublewell potential comprising of the various $\mathrm{m}_{\mathrm{j}}$ or $\mathrm{m}_{\mathrm{s}}$ states with an energy barrier $\left(U_{\mathrm{eff}}\right)$ is generated which prevents the reversal of magnetization below certain temperatures (the blocking temperature, $\left.T_{\mathrm{B}}\right){ }^{7}$ Various relaxation mechanisms including quantum tunnelling are prevalent to allow the magnetization to be lost. ${ }^{8}$

The evidence of SMM behaviour in a molecular $\mathrm{Tb}(\mathrm{III})$ complex, where the $\mathrm{Tb}(\mathrm{III})$ is sandwiched by two phthalocyanine ligands, was first reported by Ishikawa and co-workers. ${ }^{9}$ One of the intrinsic features of the lanthanide elements is that the $4 \mathrm{f}$ electrons are deeply buried inside the $[\mathrm{Xe}]$ core and are considerably shielded by the $5 \mathrm{~s}$ and $5 \mathrm{p}$ electrons. This results in an almost unquenched orbital angular momentum $(L)$ which couples with the spin angular momentum $(S)$ giving rise to the total angular momentum, $J{ }^{4 \mathrm{~d},}{ }^{10}$ Unlike transition metal ions, the magnitude of spin-orbit coupling in the case of $4 \mathrm{f}$ metal ions is comparatively much larger than the crystal field and which splits the ground ${ }^{2 \mathrm{~S}+1} \mathrm{~L}_{\mathrm{J}}$ term into different $J$ multiplets. Although the crystal field effects are small, it has a significant impact on removing the degeneracy of the $(2 J+1) m_{\mathrm{J}}$ microstates corresponding to each of the $J$ multiplets. Since the dynamics of magnetization relies on the relative energies of the ground $J$ manifold, therefore, a suitable crystal field renders the requirement of large splitting between the energy levels giving rise to high energy barrier for magnetization reversal. ${ }^{11}$ 
Soon after this discovery, many mononuclear $\operatorname{Ln}(\mathrm{III})$ complexes were reported to be SMMs with high energy barriers $\left(U_{\text {eff }}\right)$ and high blocking temperatures $\left(T_{\mathrm{B}}\right) .{ }^{12}$ Among various types of lanthanide complexes, the mononuclear complexes are of considerable interest as they provide a very good understanding of the influence of the ligand field on the observed magnetic properties. The recent reports on mononuclear Dy(III) complexes $\left[\mathrm{Dy}\left(\mathrm{Cp}^{\mathrm{ttt}}\right)_{2}\right]^{+}$ $\left(\mathrm{Cp}^{\mathrm{ttt}}=\mathrm{C}_{5} \mathrm{H}_{2}{ }^{\mathrm{t}} \mathrm{Bu}_{3}-1,2,4\right)$ and $\left[\mathrm{Dy}\left(\mathrm{Cp}^{i \mathrm{Pr} 5}\right)\left(\mathrm{Cp}^{*}\right)\right]^{+}\left(\mathrm{Cp}^{i \mathrm{Pr} 5}=\right.$ penta-iso-propylcyclopentadienyl, $\mathrm{Cp}^{*}=$ pentamethylcyclopentadienyl) revealing the highest magnetization blocking temperatures of $60 \mathrm{~K}$ and $80 \mathrm{~K}$ respectively has further spurred activity in this area of mononuclear $\operatorname{Ln}(\mathrm{III})$ complexes. $^{13}$

Although ligand fields are much smaller compared to spin-orbit coupling among lanthanide complexes, ironically the former happens to be the most decisive in controlling the performance of SMMs/SIMs. The spatial distribution of the electrons in the different $4 \mathrm{f}$ orbitals leads to inherent anisotropic shapes in the $\mathrm{Ln}(\mathrm{III})$ ions (except $\mathrm{Gd}, \mathrm{Eu}, \mathrm{La}$, and $\mathrm{Lu}$ ). Based on an electrostatic argument, Rinehart and Long have proposed a qualitative model that assists in the designing of SMMs/SIMs. ${ }^{14}$ According to this model, an axial ligand field stabilizes the oblate-shaped $\operatorname{Ln}(\mathrm{III})$ ions while a prolate-shaped $\operatorname{Ln}(\mathrm{III})$ ion requires an equatorial ligand field because such a ligand field minimizes the electrostatic repulsion between the ligands and the metal center and maximizes the molecular magnetic anisotropy. Using this clue a large number of monometallic $\operatorname{Ln}(\mathrm{III})$ complexes were prepared with interesting magnetic properties. ${ }^{15}$ Among them, the pseudo-linear pentagonal bipyramidal complexes in the DyO7, DyClO6, DyXN4O2 $(\mathrm{X}=\mathrm{Cl}$ and $\mathrm{Br})$, and DyN5O2 coordination environment with strong axial ligand field and weak equatorial ligand field stand out as the most effective systems for the observation of high energy barriers of magnetization reversal. $^{16}$ 
We have been utilizing various types of multidentate ligands for the synthesis of mononuclear Ln(III) complexes. In our previous work, we have synthesized mononuclear pentagonal bipyramidal Ln(III) complexes by employing a pentadentate chelating ligand that provides a rigid equatorial plane. ${ }^{17}$ The axial sites in these complexes were occupied by the chloride ions which are considerably weak field ligands compared to $\mathrm{N}$ and $\mathrm{O}$ donors present in the ligand backbone. We have thoroughly studied the magnetic properties of the Dy(III), $\mathrm{Tb}$ (III) and the diluted Dy(III) (in an isostructural Y(III) host) complexes which reveal the molecular origin of slow magnetic relaxation in the Dy(III) derivative with an energy barrier of magnetization reversal of $70 \mathrm{~K} \cdot{ }^{17}$ To understand the role of the axial ligands in this system we have now prepared a series of neutral mononuclear PBP complexes, $\left[\left(\mathrm{L}^{2} \mathrm{Ln}^{\mathrm{III}}\left(\mathrm{R}_{3} \mathrm{PO}\right) \mathrm{Cl}\right]\right.$ [(Ln = Gd (1), Tb (2), Dy (3), Er (5); R = cyclohexyl) and (Ln = Dy (4); R = phenyl) $]$ where one phosphine oxide ligand replaces one of the two chloride ligands in the axial sites. Herein, we report the synthesis, structural characterization and magnetic properties of 1-5. The difference in the magnetic properties has been analyzed by ab initio CASSCF/RASSISO/SINGLE_ANISO calculation which provides the insight to design the potential SIM.

\section{Experimental Section}

Materials and methods. All the reagents and solvents used for the syntheses were used as received from commercial sources. The organic ligand 2,6-diacetylpyridine bisbenzoylhydrazone $\left(\mathrm{H}_{2} \mathrm{~L}\right)$ was synthesized following a reported procedure. ${ }^{18}$ Fourier transform infrared (FT-IR) spectroscopy was performed with a Bruker FT-IR spectrometer. Elemental analyses were performed with a Perkin-Elmer 2400 series II instrument. Powder X-ray diffraction study was performed on finely ground polycrystalline material with Bruker D8 Advance Powder X-ray diffractometer. 
Magnetic Measurements. Magnetic measurements for all the samples were carried out with a Quantum Design MPMS 5S SQUID magnetometer in the temperature range 2-300 K. The measurements were performed on polycrystalline samples. The crystalline powders of the complexes were mixed with grease (except for Gd derivative) and put in gelatin capsules. The temperature dependences of the magnetization were measured in an applied field of $1 \mathrm{kOe}$, and the isothermal field dependence of the magnetizations were collected up to $5 \mathrm{~T}$. The molar susceptibility $\left(\chi_{\mathrm{M}}\right)$ was corrected for sample holder and for the diamagnetic contribution of all the atoms by using Pascal's tables. AC susceptibility data have been collected in zero field and with applied fields in the frequency range 1-1500 Hz.

X-ray crystallographic studies. The single-crystal X-ray diffraction data of 1-5 were collected on a Rigaku Xtal LAB X-ray Diffractometer system equipped with a CCD area detector and operated at $30 \mathrm{~W}$ power $(50 \mathrm{kV}, 0.6 \mathrm{~mA})$ to generate $\mathrm{MoK} \alpha$ radiation $(\lambda=$ $0.71073 \AA$ A) at $120(2) \mathrm{K}$. Data were integrated using CrysAlis ${ }^{\text {Pro }}$ software with a narrow frame algorithm. Data were subsequently corrected for absorption by the program SCALE3 ABSPACK scaling algorithm. ${ }^{13 a}$ All the structures were solved by the direct methods in SHELXTL $^{19}$ and refined by the full-matrix least-squares method on $\mathrm{F}^{2}$ (SHELXL-2014) $^{20}$ using the Olex-2 software. ${ }^{21}$ All the non-hydrogen atoms were refined with anisotropic thermal parameters. All the hydrogen atoms were included in idealized positions, and a riding model was used. All the mean plane analyses and crystallographic figures have been generated using the DIAMOND software (version $3.2 \mathrm{k}){ }^{22}$ The crystal data and refinement parameters for 1-5 are summarized in Table 1. More details on the crystallographic data are given in the X-ray crystallographic files in the CIF format.

\section{Synthesis}

General procedure. The following general protocol was employed for the synthesis of complexes 1-5. 
The organic ligand, $\mathrm{H}_{2} \mathrm{~L}$ (1 eq.) was suspended in $30 \mathrm{~mL}$ of EtOH and cyclohexyl/phenyl phosphine oxide (1 eq.) was added to it. To this white cloudy solution, the respective $\mathrm{LnCl}_{3} \cdot 6 \mathrm{H}_{2} \mathrm{O}$ (1 eq.) salts were added which results in a yellow solution. The reaction mixture was then heated under reflux conditions for $1 \mathrm{~h}$ and allowed to cool to room temperature. To this solution 2 eq. of $\mathrm{NEt}_{3}$ was added and the solution further stirred at room temperature for 10 minutes. The solvent was evaporated to dryness and the resulting yellow precipitate was washed with diethyl ether. The dried yellow precipitate was then dissolved in $10 \mathrm{~mL}$ of EtOH and filtered. The filtrate was kept under vapor diffusion with diethyl ether to afford needleshaped crystals suitable for X-ray crystallography after one week. The stoichiometry of the reactants involved in each reaction, yield of the products, and their characterization data are provided below:

[(L)Gd(Cy $\left.\left.\mathrm{Cy}_{3} \mathrm{PO}\right) \mathrm{Cl}\right](\mathbf{1}) . \mathrm{H}_{2} \mathrm{~L}(0.040 \mathrm{~g}, 0.100 \mathrm{mmol}), \mathrm{GdCl}_{3} \cdot 6 \mathrm{H}_{2} \mathrm{O}(0.037 \mathrm{~g}, 0.100 \mathrm{mmol})$, $\mathrm{Cy}_{3} \mathrm{PO}(0.030 \mathrm{~g}, 0.100 \mathrm{mmol})$, and $\mathrm{Et}_{3} \mathrm{~N}(28 \mu \mathrm{L}, 0.200 \mathrm{mmol})$ were used. Yield: $0.053 \mathrm{~g}$, $60 \%$ (based on Gd). M.P.: >250 ${ }^{\circ} \mathrm{C}$. IR ( $\left.\mathrm{KBr} v / \mathrm{cm}^{-1}\right)$ : 3439(br), 3062(w), 2929(s), 2852(m), 1632(w), 1587(m), 1552(m), 1503(s), 1446(m), 1411(m), 1371(s), 1324(m), 1297(m), 1258(w), 1197(w), 1169(m), 1148(m), 1103(s), 1069(w), 1040(s), 987(w), 895(m), 854(w), 809(m), 744(m), 716(s), 679(s), 650(w), 534(m). Anal. Calcd for $\mathrm{C}_{41} \mathrm{H}_{52} \mathrm{Cl}_{1} \mathrm{~N}_{5} \mathrm{O}_{3} \mathrm{P}_{1} \mathrm{Gd}_{1}$ (886.57): C, 55.55; H, 5.91; N, 7.90. Found: C, 55.21; H, 6.36; N, 7.61.

$\left[(\mathrm{L}) \mathrm{Tb}\left(\mathrm{Cy} y_{3} \mathrm{PO}\right) \mathrm{Cl}\right](2) . \mathrm{H}_{2} \mathrm{~L}(0.040 \mathrm{~g}, 0.100 \mathrm{mmol}), \mathrm{TbCl}_{3} \cdot 6 \mathrm{H}_{2} \mathrm{O}(0.037 \mathrm{~g}, 0.100 \mathrm{mmol})$, $\mathrm{Cy}_{3} \mathrm{PO}(0.030 \mathrm{~g}, 0.100 \mathrm{mmol})$, and $\mathrm{Et}_{3} \mathrm{~N}(28 \mu \mathrm{L}, 0.200 \mathrm{mmol})$ were used. Yield: $0.059 \mathrm{~g}$, $67 \%$ (based on Tb). M.P.: >250 ${ }^{\circ} \mathrm{C}$. IR ( $\left.\mathrm{KBr} v / \mathrm{cm}^{-1}\right)$ : 3441(br), 3064(w), 2927(s), 2854(m), 1634(w), 1587(m), 1552(m), 1505(s), 1446(m), 1409(m), 1368(s), 1326(m), 1299(m), 1256(w), 1197(w), 1169(m), 1148(m), 1105(s), 1067(w), 1040(s), 987(w), 897(m), 856(w), 809(m), 744(m), 714(s), 679(s), 652(w), 532(m). Anal. Calcd for $\mathrm{C}_{41} \mathrm{H}_{52} \mathrm{Cl}_{1} \mathrm{~N}_{5} \mathrm{O}_{3} \mathrm{P}_{1} \mathrm{~Tb}_{1}$ (888.25): C, 55.44; H, 5.90; N, 7.88. Found: C, 55.02; H, 6.56; N, 7.75. 
$\left[(\mathrm{L}) \mathrm{Dy}\left(\mathrm{Cy}_{3} \mathrm{PO}\right) \mathrm{Cl}\right](3) . \mathrm{H}_{2} \mathrm{~L}(0.040 \mathrm{~g}, 0.100 \mathrm{mmol}), \mathrm{DyCl}_{3} \cdot 6 \mathrm{H}_{2} \mathrm{O}(0.038 \mathrm{~g}, 0.100 \mathrm{mmol})$, $\mathrm{Cy}_{3} \mathrm{PO}(0.030 \mathrm{~g}, 0.100 \mathrm{mmol})$, and $\mathrm{Et}_{3} \mathrm{~N}(28 \mu \mathrm{L}, 0.200 \mathrm{mmol})$ were used. Yield: $0.061 \mathrm{~g}$, 69\% (based on Dy). M.P.: >250 ${ }^{\circ} \mathrm{C}$. IR ( $\left.\mathrm{KBr} v / \mathrm{cm}^{-1}\right)$ : 3443(br), 3064(w), 2929(s), 2852(m), 1630(w), 1587(m), 1554(m), 1505(s), 1446(m), 1411(m), 1368(s), 1326(m), 1299(m), 1258(w), 1197(w), 1171(m), 1150(m), 1105(s), 1067(w), 1042(s), 989(w), 897(m), 854(w), 809(m), 744(m), 714(s), 679(s), 650(w), 532(m). Anal. Calcd for $\mathrm{C}_{41} \mathrm{H}_{52} \mathrm{Cl}_{1} \mathrm{~N}_{5} \mathrm{O}_{3} \mathrm{P}_{1} \mathrm{Dy}_{1}$ (891.82): C, 55.22; H, 5.88; N, 7.85. Found: C, 54.85; H, 6.39; N, 7.71.

[(L) $\left.\mathrm{Y}_{0.90} \mathrm{Dy}_{0.10}\left(\mathrm{Cy}_{3} \mathrm{PO}\right) \mathrm{Cl}\right]$ (3'): Anal. Calcd for $\mathrm{C}_{41} \mathrm{H}_{52} \mathrm{Cl}_{1} \mathrm{~N}_{5} \mathrm{O}_{3} \mathrm{P}_{1} \mathrm{Y}_{0.90} \mathrm{Dy}_{0.10}: \mathrm{C}, 60.19 ; \mathrm{H}$, 6.41; N, 8.56. Found: C, 59.91; H, 6.52; N, 8.39.

$\left[(\mathrm{L}) \mathrm{Dy}\left(\mathrm{Ph}_{3} \mathrm{PO}\right) \mathrm{Cl}\right](4) . \mathrm{H}_{2} \mathrm{~L}(0.040 \mathrm{~g}, 0.100 \mathrm{mmol}), \mathrm{DyCl}_{3} \cdot 6 \mathrm{H}_{2} \mathrm{O}(0.038 \mathrm{~g}, 0.100 \mathrm{mmol})$, $\mathrm{Ph}_{3} \mathrm{PO}(0.028 \mathrm{~g}, 0.100 \mathrm{mmol})$, and $\mathrm{Et}_{3} \mathrm{~N}(28 \mu \mathrm{L}, 0.200 \mathrm{mmol})$ were used. Yield: $0.064 \mathrm{~g}, 72 \%$ (based on Dy). M.P.: >250 ${ }^{\circ} \mathrm{C}$. IR ( $\left.\mathrm{KBr} v / \mathrm{cm}^{-1}\right)$ : 3429(br), 3054(w), 2919(s), 1632(w), 1587(m), 1552(m), 1499(m), 1438(m), 1409(), 1366(s), 1325(m), 1297(m), 1258(w), 1160(w), 1122(m), 1093(m), 1067(s), 1044(w), 989(w), 897(m), 809(m), 744(m), 714(s), 691(), 650(2), 540(m). Anal. Calcd for $\mathrm{C}_{41} \mathrm{H}_{34} \mathrm{Cl}_{1} \mathrm{~N}_{5} \mathrm{O}_{3} \mathrm{P}_{1} \mathrm{Dy}_{1}$ (873.68): C, 56.37; H, 3.92; $\mathrm{N}$, 8.02. Found: C, 55.98; H, 3.61; N, 7.89

$\left[(\mathrm{L}) \mathrm{Er}\left(\mathrm{Cy}{ }_{3} \mathrm{PO}\right) \mathrm{Cl}\right](5) . \mathrm{H}_{2} \mathrm{~L}(0.040 \mathrm{~g}, 0.100 \mathrm{mmol}), \mathrm{ErCl}_{3} \cdot 6 \mathrm{H}_{2} \mathrm{O}(0.038 \mathrm{~g}, 0.100 \mathrm{mmol})$, $\mathrm{Cy}_{3} \mathrm{PO}(0.030 \mathrm{~g}, 0.100 \mathrm{mmol})$, and $\mathrm{Et}_{3} \mathrm{~N}(28 \mu \mathrm{L}, 0.200 \mathrm{mmol})$ were used. Yield: $0.065 \mathrm{~g}$, 73\% (based on Er). M.P.: >250 IR (KBr v/cm $\left.{ }^{-1}\right)$ : 3447(br), 3068(w), 2929(s), 2852(m), 1636(w), 1587(m), 1554(m), 1505(s), 1446(m), 1413(m), 1366(s), 1326(m), 1299(m), 1260(w), 1199(w), 1169(m), 1152(m), 1107(s), 1067(w), 1044(s), 989(w), 897(m), 854(w), 809(m), 746(m), 714(s), 679(s), 650(w), 534(m). Anal. Calcd for $\mathrm{C}_{41} \mathrm{H}_{52} \mathrm{Cl}_{1} \mathrm{~N}_{5} \mathrm{O}_{3} \mathrm{P}_{1} \mathrm{Er}_{1}$ (896.58): C, 54.93; H, 5.85; N, 7.78. Found: C, 54.65; H, 6.33; N, 7.53. 


\section{Computational Details}

Post-Hartree-Fock ab initio calculations were carried out on the X-ray crystal structures of all complexes using the CASSCF+RASSI-SO+SINGLE_ANISO approach as implemented in MOLCAS 8.2 programme package. ${ }^{23}$ The relativistic effects of the lanthanide ions have been incorporated using the DKH Hamiltonian. ${ }^{24}$ The basis set of all the atoms (Table S8 in ESI) has been taken from the ANO-RCC library implemented in MOLCAS 8.2 suite. First, we have performed CASSCF calculations by considering 8,9 and 11 electrons in the seven $4 \mathrm{f}$ orbitals of $\mathrm{Tb}(\mathrm{III}), \mathrm{Dy}(\mathrm{III})$ and $\mathrm{Er}(\mathrm{III})$ ions in their respective complexes. Using this active space, we have computed 7 septet, 140 quintet and 195 triplet states for $\mathrm{Tb}(\mathrm{III}), 21$ sextet states for Dy(III), 35 quartet and 112 doublet states for $\operatorname{Er}(\mathrm{III})$ ion. These spin free states of each complex were mixed by RASSI-SO to calculate the spin-orbit energy levels. Finally, the $\mathrm{g}$ tensors and mechanism of magnetization relaxations were estimated using the SINGLE_ANISO which interfaced with the RASSI-SO energies. In a nutshell, CASSCF/RASSI-SO/SINGLE_ANISO method was used to compute the magnetic anisotropy, energy of the spin free and spin-orbit states and the magnetic relaxation dynamics.

\section{Results and Discussion}

Synthetic aspects. The PBP geometry is regarded as one of the most promising coordination geometries around the $\mathrm{Ln}(\mathrm{III})$ center that can bring axiality in the ground state of $\mathrm{Ln}(\mathrm{III})$ ions provided the axial sites are occupied by comparatively strong donor ligands. We have previously reported the synthesis of mononuclear pentagonal bipyramidal $\operatorname{Ln}(\mathrm{III})$ complexes using a pentadentate chelating ligand which effectively provides a rigid equatorial plane. In these complexes, the two axial sites were occupied by chloride ions which can be regarded as weak field ligands compared to the $\mathrm{N}$ and $\mathrm{O}$ donor atoms of the pentadentate chelating 
ligand. Theoretical studies accompanied by experimental evidence show that oblate shaped Ln(III) ions show high energy barriers of magnetization in the PBP geometry when the axial sites are occupied by relatively strong donor ligands compared to the equatorial sites. Keep this in mind we have chosen tri-alkyl/aryl phosphine oxides to replace the chloride ions in the axial sites. Accordingly, when we treated the ligand $\mathrm{H}_{2} \mathrm{~L}$ with lanthanide chlorides in the presence of phosphine oxides followed by addition of base we obtained neutral mononuclear $\left[(\mathrm{L}) \mathrm{Ln}^{\mathrm{III}}\left(\mathrm{R}_{3} \mathrm{PO}\right) \mathrm{Cl}\right](\mathrm{Ln}=\mathrm{Dy} \mathrm{Tb}, \mathrm{Gd}, \mathrm{Er}$ when $\mathrm{R}=$ cyclohexyl; $\mathrm{Ln}=$ Dy when $\mathrm{R}=$ phenyl $)$ complexes (Scheme 1).

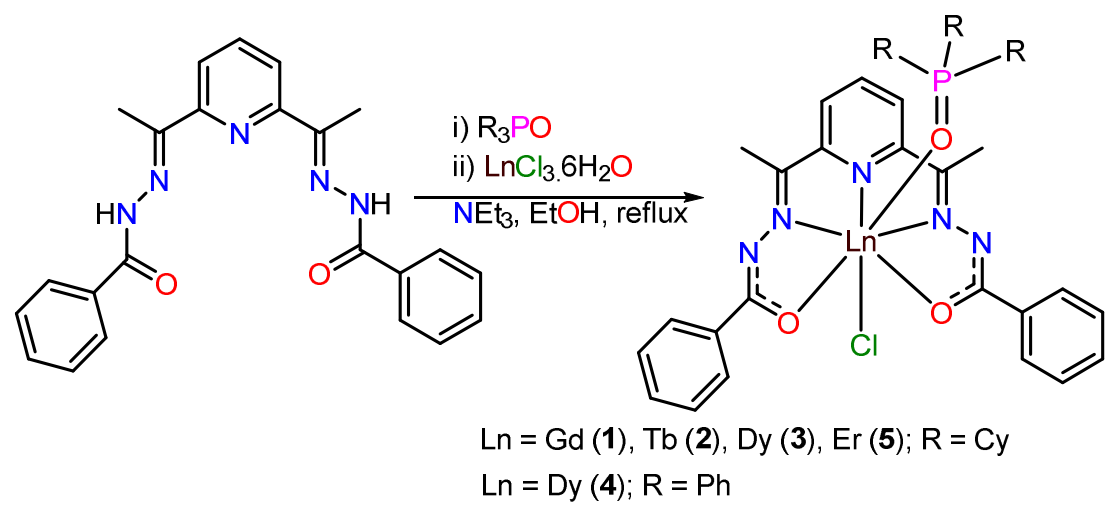

Scheme 1. Reaction scheme for the synthesis of 1-5.

\section{X-ray Crystallography}

The complexes $\mathbf{1}, \mathbf{3}$ and $\mathbf{5}$ crystallize in the monoclinic crystal system with $P 2{ }_{1} / \mathrm{c}$ (for 3) and $P 2_{1} / \mathrm{n}$ (for $\mathbf{1}$ and 5) space groups whereas the complexes $\mathbf{2}$ and $\mathbf{4}$ crystallize in the triclinic crystal system with $P-1$ space group. Crystallographic data and refinement parameters of all the complexes are given in Table S1. The overall molecular structures of the complexes 1-5 are essentially identical. The molecular structure of complex 3 is shown in Figure 1, while those of 1, 2, 4 and 5 are given in the Supporting Information (Figures S1-S4). In view of the structural similarities present in the complexes we discuss below the molecular structures of complexes $\mathbf{3}$ and $\mathbf{4}$. 


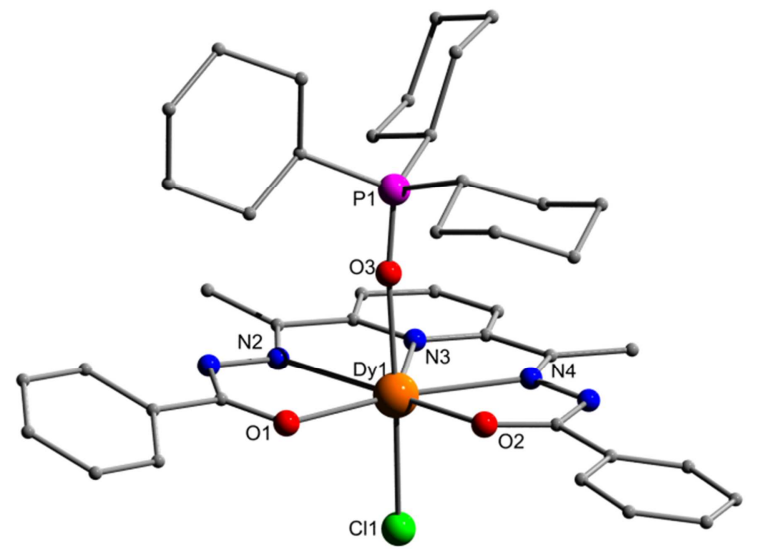

Figure 1. Molecular structure of complex 3. (The $\mathrm{H}$ atoms are removed for clarity)

The complexes are formed by the coordination action of ligand pyridyl $\mathrm{N}$ atom, two imino $\mathrm{N}$ atoms, and two carboxy $\mathrm{O}$ atoms in the equatorial positions. One of the two axial sites is occupied by one chloride anion in both the two complexes. The remaining axial site is occupied by one $\mathrm{Cy}_{3} \mathrm{PO}$ ligand in the case of 3 and $\mathrm{Ph}_{3} \mathrm{PO}$ ligand in the case of $\mathbf{4}$. The ligand upon chelation with the $\operatorname{Ln}(\mathrm{III})$ ions generates four five-membered rings revealing its excellent ability to stabilize the $\operatorname{Ln}(\mathrm{III})$ ions in its pentagonal coordination environment. The equatorial $\mathrm{Dy}-\mathrm{O} / \mathrm{N}$ bond distances are in the range of 2.259(2)-2.462(2) $\AA$ for 3 and 2.282(2)-2.456(2) $\AA$ for 4. The Dy- $\mathrm{O}_{\text {axial }}$ bond distances are 2.237(2) for 3 and 2.275(2) for 4. The $\mathrm{Dy}-\mathrm{Cl}$ bond distances are 2.625(8) $\AA$ for 3 and 2.622 (7) $\AA$ for 4. Interestingly, the Dy $-\mathrm{O}_{\text {axial }}$ bond distance in both 3 and $\mathbf{4}$ are shorter compared to the Dy- $\mathrm{O}_{\text {equatorial }}$ distances (Table S2 and Table S4) indicating the strong-field nature of the phosphine oxide ligand in comparison to the equatorial oxygen donors. The $\mathrm{O}_{\text {phos }}-\mathrm{Dy}-\mathrm{Cl}$ bond angles are $169.62(5)^{\circ}$ for 3 and 174.07(5) ${ }^{\circ}$ for 4 . The immediate coordination environment the $\operatorname{Ln}(\mathrm{III})$ ions are analyzed with Continuous-Shape Measures using the SHAPE program. ${ }^{25}$ It reveals a distorted pentagonal bipyramid geometry around the Dy(III) ions with $D_{5 \mathrm{~h}}$ (pseudo) CF symmetry (Table S3, see ESI). The pentagonal bipyramidal geometry of the Dy(III) ion in complex 3 is shown in Figure 2 (left). The shortest intermolecular 


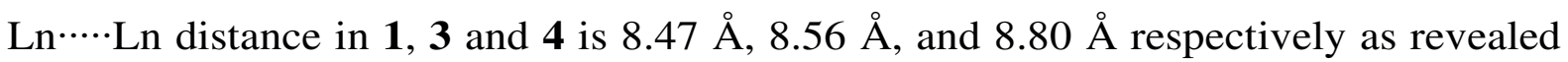
in the solid-state packing diagram (see Figure 2 (right) for complex $\mathbf{3}$ and Figures S5 and S6 for 1 and 4). The solid state phase purity of the complex 3' was confirmed by powder X-ray diffraction studies (Figure S7 see ESI). The selected bond lengths and bond angles of complexes 1, 2, 4 and $\mathbf{5}$ are summarized in Table S4 (see ESI).
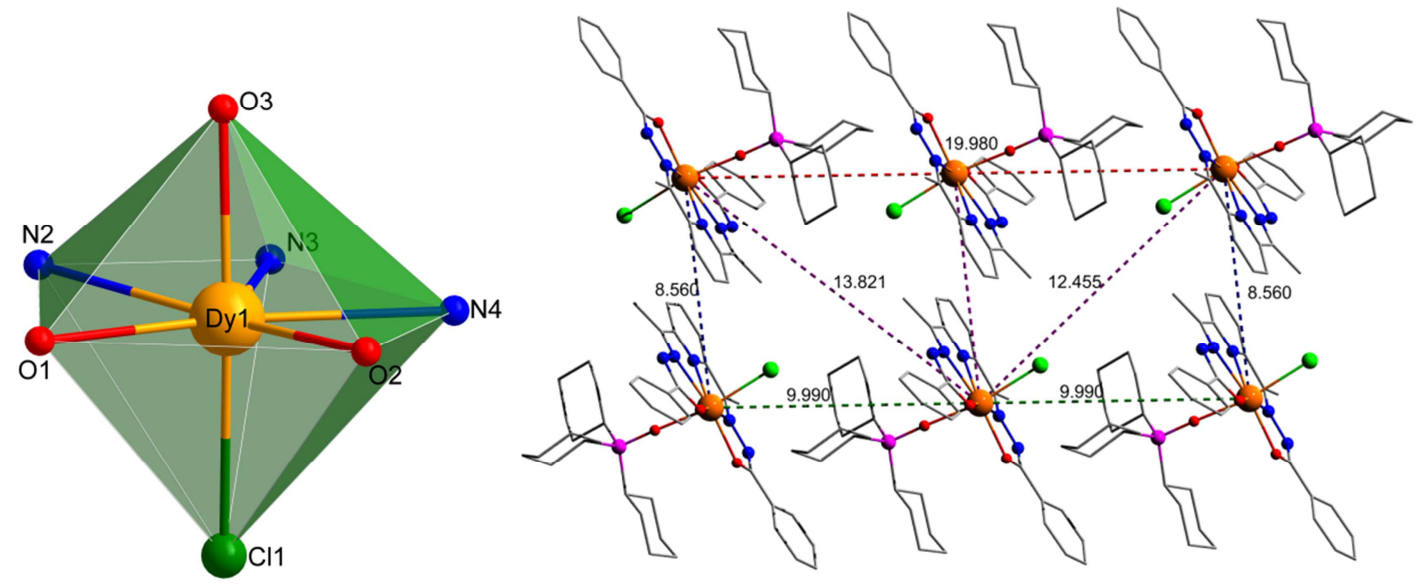

Figure 2. (left) Coordination polyhedra of Dy(III) and (right) solid-state packing diagram of complex 3 .

\section{Magnetic Properties}

The temperature dependence of the molar magnetic susceptibility $\left(\chi_{\mathrm{M}}\right)$ for $\mathbf{1 - 3}$ and $\mathbf{5}$ are plotted in Figure 3 and the field dependence of the magnetization for these compounds can be found in Figure S9. The corresponding behavior for $\mathbf{4}$ is summarized in Figure S8. The values of the product of the molar magnetic susceptibility with temperature, $\chi_{\mathrm{M}} \mathrm{T}$ (in $\mathrm{cm}^{3} \mathrm{~mol}^{-1} \mathrm{~K}$ ) found at $300 \mathrm{~K}$ are $7.85(\mathrm{Gd}), 11.79(\mathrm{~Tb}), 14.14$ and $14.10(\mathrm{Dy})$, and $11.18(\mathrm{Er})$, in good accordance with the expected values expected for the isolated ions (i.e. 7.88, 11.81, 14.17, and $11.48 \mathrm{~cm}^{3} \mathrm{~mol}^{-1} \mathrm{~K}$, respectively). For the $\mathrm{Tb}, \mathrm{Dy}$, and Er derivatives the $\chi_{\mathrm{M}} \mathrm{T}$ slowly decreases as $\mathrm{T}$ is lowered in agreement with the anticipated crystal field effect. The absence of any contribution from intermolecular exchange interactions is confirmed by the perfect Curie behavior down to $2 \mathrm{~K}$ for $\mathrm{Gd}$. For the $\mathrm{Tb}$ and Dy derivatives, the field-dependent 
magnetization at 2-5 K show a fast rise at lower field regions and remain almost unchanged above $15 \mathrm{kOe}($ at $2 \mathrm{~K}$ ) to reach $4.8 \mu \mathrm{B}(2), 5.14$ (3), and 5.09 (4) at high field (5 T). To probe the dynamics of the magnetization relaxation, AC susceptibility behavior was investigated without and with applied static fields. No out-of-phase component $\left(\chi^{\prime \prime}\right)$ were found for the $\mathrm{Tb}$ and Er derivatives down to $2 \mathrm{~K}$ (see Figure S10 in ESI). However, the Dy complexes 3 and 4 exhibited a $\chi^{\prime \prime}$ s signal but no maximum was observed above $2 \mathrm{~K}$ (see Figure S10 in ESI).

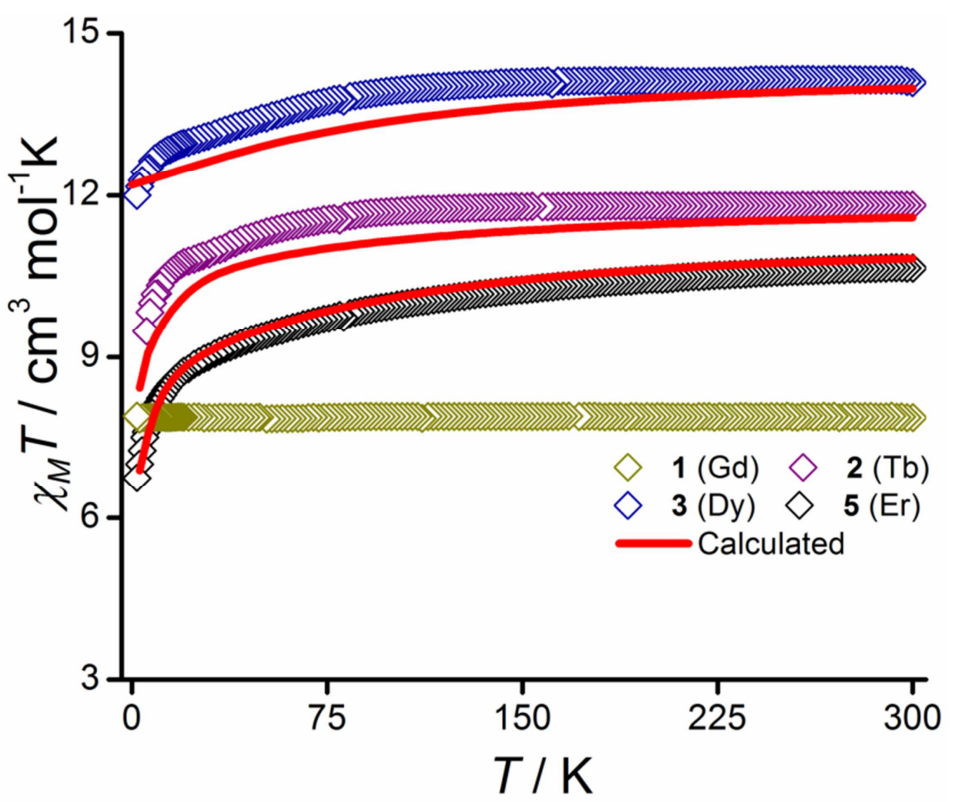

Figure 3. Temperature dependence of the product of the molar magnetic susceptibility with temperature, $\chi_{\mathrm{M}} \mathrm{T}$, under $1 \mathrm{kOe}$ applied magnetic field for complexes 1-3 and 5. Solid red lines represent the $a b$ initio calculated data. The computed data for 5 was reduced by $2 \%$ to meet the experimentally observed.

Such a behaviour was suggesting relaxation driven by QTM which was reduced by applying a static field. For 3, the optimum applied field was estimated at $H_{\mathrm{DC}}=1 \mathrm{kOe}$ (See Figure S11). AC susceptibility study carried out in this field within the frequency domain $1-1500 \mathrm{~Hz}$ yielded well-defined maxima for $\chi^{\prime \prime}{ }_{M}$ between 4 and $18 \mathrm{~K}$ (Figure 4). Relaxation times $(\tau)$ 
have been assessed by fitting $\chi^{\prime \prime}{ }_{M}=f($ Frq $)$ for different temperatures with an extended Debye model, best fit parameters are gathered in Table S5. The very small $a$ parameter is indicative for a narrow distribution width for the relaxation time over the whole temperature domain, suggesting that mainly one relaxation process is operative. The temperature dependence of the relaxation time, plotted in log scale in Figure 4, develops to a more linear variation above $10 \mathrm{~K}$, which is the behavior anticipated for a thermally activated process (Orbach). Deviation from linearity for lower $T$ indicates that other processes also come into play. Analysis of the behavior over the whole $T$ range was obtained by summing the contributions of the Orbach, Raman, and direct processes $\left(\tau=\tau_{0} \exp \left(U_{\text {eff }} / k_{\mathrm{B}} T\right)+1 /\left(\mathrm{C} T^{\mathrm{n}}\right)+1 /(\mathrm{A} T)\right.$. The latter were required to reproduce the lower $T$ behavior. Best fit gave a thermal energy barrier for magnetization reversal, $U_{\text {eff }} / k_{\mathrm{B}}=204 \pm 3 \mathrm{~K}$ with $\tau_{0}=(6 \pm 1) \times 10^{-9} \mathrm{~s}, \mathrm{C}=0.015 \mathrm{~K}^{-1} \mathrm{~s}^{-1}, \mathrm{n}=4.5$, and $\mathrm{A}=-1.30$ $\mathrm{s}^{-1}$.

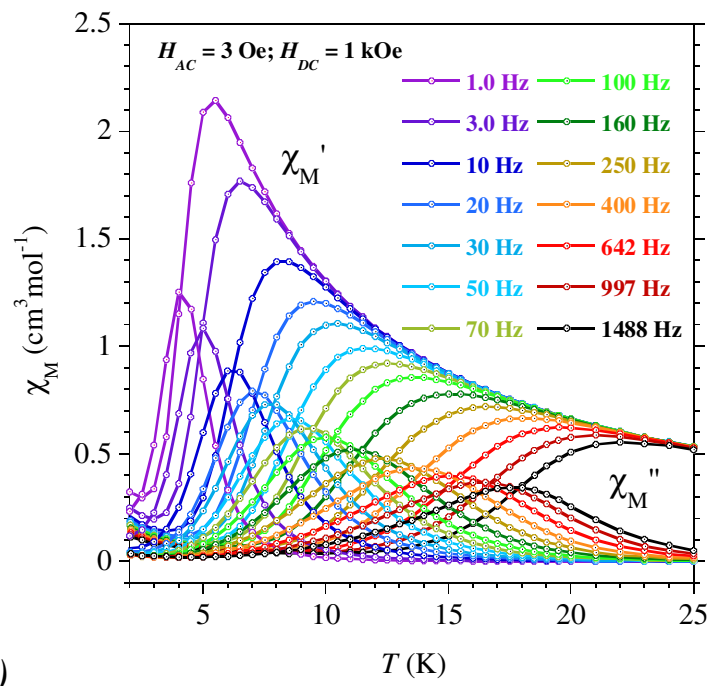

(a)

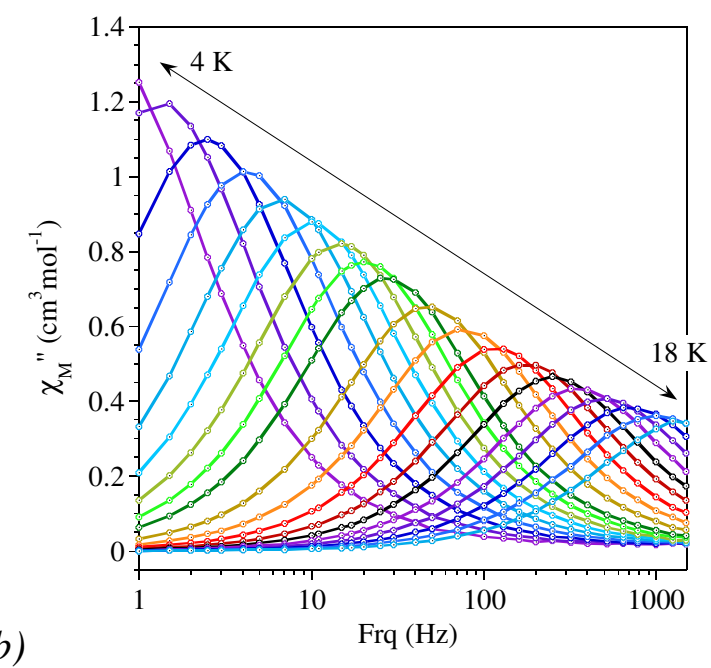



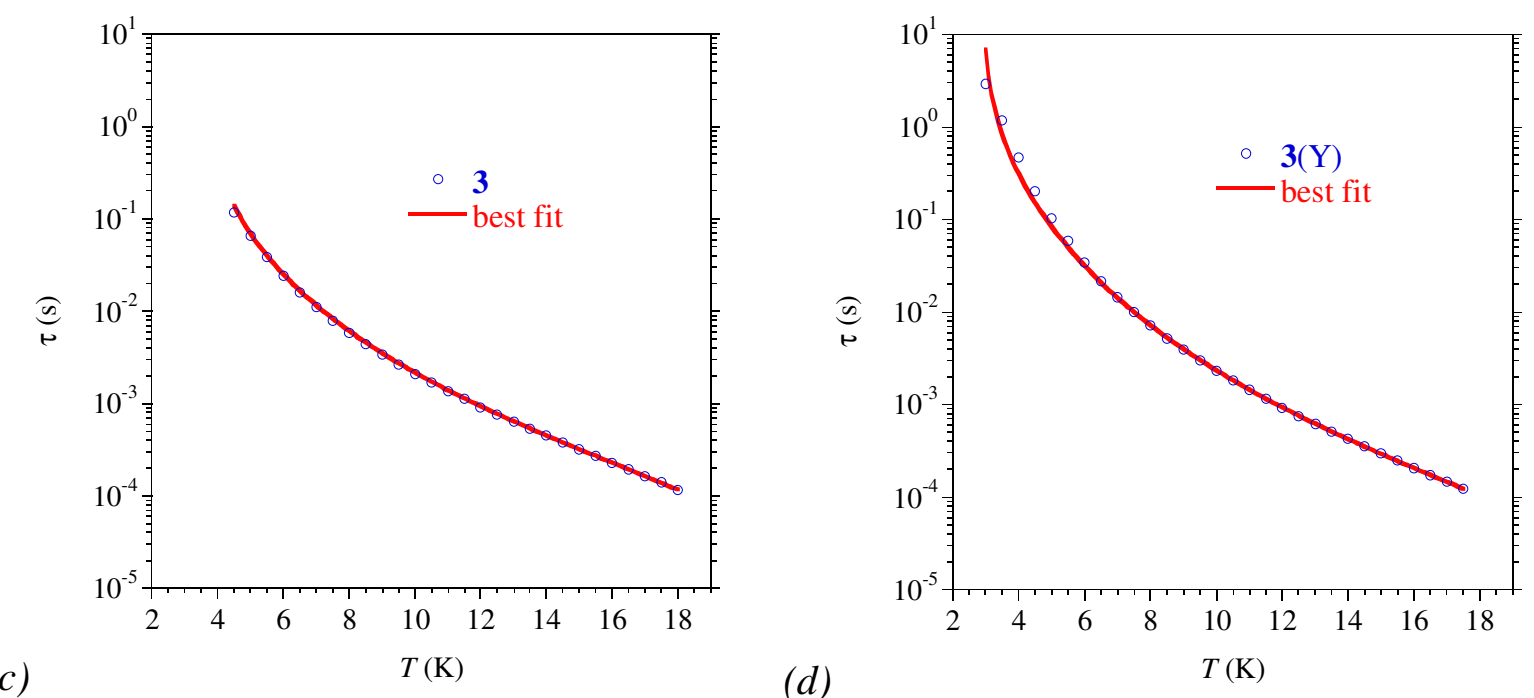

Figure 4. $(a, b)$ AC susceptibility behaviors for 3; (c) temperature dependence of the relaxation times for $\mathbf{3}$, and $(d)$ for diluted compound $\mathbf{3}$; the solid red lines are the best fits (see text).

The dilution of $\mathbf{3}$ in a matrix of isomorphous $\mathrm{Y}$ complex, $\mathbf{3}^{\prime}$ hereafter, gave very similar results (see Figure S12 in ESI). For this sample however, a maximum was observed in the $\chi^{\prime \prime}{ }_{\mathrm{M}}=f(T)$ behavior in zero field but a QTM contribution was discernible at low temperature. This was suppressed upon applying a small DC field of 750 Oe. The temperature dependence of the relation times between 2 and $17.5 \mathrm{~K}$ (Figure 4 and Table S6) parallels that obtained for the pure Dy derivative 3, and contributions of the Orbach, Raman, and direct processes had to be taken into account to reach a good modeling. Best fit to the experimental data for $\mathbf{3}^{\prime}$ yielded $U_{\text {eff }} / k_{\mathrm{B}}=208 \pm 5 \mathrm{~K}, \tau_{0}=(6 \pm 2) \times 10^{-9} \mathrm{~s}, \mathrm{C}=4.3 \times 10^{-3} \mathrm{~K}^{-1} \mathrm{~s}^{-1}, \mathrm{n}=5.0$, and $\mathrm{A}=-0.30 \mathrm{~s}^{-1}$. The comparison of the behavior for $\mathbf{3}$ and its diluted form $\mathbf{3}$ ' shows that the observed behavior is clearly of molecular origin.

The replacement of $\mathrm{OPCy}_{3}$ for $\mathrm{OPPh}_{3}$ in the apical position of Dy appeared to have no significant incidence on the magnetic behaviours; the AC susceptibility features for 4 (Figure 
S13 and Table S7 in ESI) are very similar to that obtained for 3. To reproduce the temperature dependence of the relaxation time for $\mathbf{4}$ required to consider contributions from Orbach, Raman and direct processes, best fit to the experimental behavior gave $U_{\text {eff }} / k_{\mathrm{B}}=241$ $\pm 7 \mathrm{~K}, \tau_{0}=(2.3 \pm 0.9) \times 10^{-10} \mathrm{~s}, \mathrm{C}=(5.97 \pm 0.03) \times 10^{-3} \mathrm{~K}^{-1} \mathrm{~s}^{-1}, \mathrm{n}=5.1$, and $\mathrm{A}=0.2 \pm 0.7 \mathrm{~s}^{-1}$.

It is satisfying to see that the energy barrier for magnetization reversal, $U_{\text {eff }} / k_{\mathrm{B}}$, for the Dy(III) complexes reported herein is significantly increased with respect to the homologue complex with $\mathrm{Cl}^{-}$ligands in the apical positions. This could be attributed to the stronger axial field due to the phosphine oxide ligand. A detailed comparison of the bond and magnetic properties of the present complexes with the reported pentagonal bipyramidal Dy(III) complexes having other equatorial ligands (including monodentate ones) and axial groups of various crystal field strengths are given in Table 1.

Table 1. Selected bond and magnetic parameters of PBP Dy(III) complexes

\begin{tabular}{|c|c|c|c|c|c|c|c|}
\hline $\begin{array}{l}\text { Sl. } \\
\text { No. }\end{array}$ & Complex & $\begin{array}{c}\mathbf{L}_{\mathbf{a x}}-\mathbf{L n}-\mathbf{L}_{\mathrm{ax}} \\
\left({ }^{\circ}\right)\end{array}$ & $\begin{array}{l}\text { Average } \\
\text { axial Ln- } \\
\text { O/Ln-X } \\
\text { distance } \\
(\AA)\end{array}$ & $\begin{array}{c}\text { Average } \\
\text { equatorial Ln- } \\
\text { O/Ln-N/Ln-X } \\
\text { distance } \\
(\AA)\end{array}$ & $\begin{array}{c}U_{\text {eff }}(\mathbf{K}) \\
\left(\mathbf{H}_{\text {dc }}\right)\end{array}$ & $\tau_{\mathrm{o}}(\mathbf{s})$ & Ref. \\
\hline 1 & {$\left[\mathrm{Dy}\left(\mathrm{O}^{t} \mathrm{Bu}\right)_{2}(\mathrm{py})_{5}\right]\left[\mathrm{BPh}_{4}\right]$} & 155.80 & 2.112 & 2.557 & $\begin{array}{c}1815 \\
(0 \mathrm{Oe})\end{array}$ & $1.17 \times 10^{-12}$ & {$\left[{ }^{16 \mathrm{e}}\right]$} \\
\hline 2 & [Dy(bbpen)Br] & 155.79 & 2.163 & $2.586 / 2.851$ & $\begin{array}{c}1025 \\
(0 \mathrm{Oe})\end{array}$ & $4.21 \times 10^{-12}$ & {$\left[{ }^{16 c}\right]$} \\
\hline 3 & $\begin{array}{l}{\left[\mathrm{Dy}\left({ }^{t} \mathrm{BuO}\right) \mathrm{Cl}(\mathrm{THF})_{5}\right]} \\
{\left[\mathrm{BPh}_{4}\right] \cdot 2 \mathrm{THF}}\end{array}$ & 178.28 & $2.043 / 2.662$ & 2.410 & $\begin{array}{c}950 \\
(0 \mathrm{Oe})\end{array}$ & $3 \times 10^{-12}$ & {$\left[{ }^{26}\right]$} \\
\hline 4 & [Dy(bbpen)Cl] & 154.24 & 2.166 & $2.584 / 2.682$ & $\begin{array}{l}708 \\
(0 \mathrm{Oe})\end{array}$ & $9.46 \times 10^{-11}$ & {$\left[{ }^{16 c}\right]$} \\
\hline 5 & $\begin{array}{l}{\left[\mathrm{L}_{2}^{1} \mathrm{Dy}\left(\mathrm{H}_{2} \mathrm{O}\right)_{5}\right][\mathrm{I}]_{3} \cdot\left(\mathrm{L}^{1}\right)_{2} .} \\
\mathrm{H}_{2} \mathrm{O}\end{array}$ & 177.9 & 2.205 & 2.363 & $\begin{array}{l}651 \\
(0 \mathrm{Oe})\end{array}$ & $5.63 \times 10^{-12}$ & {$\left[{ }^{16 \mathrm{~b}}\right]$} \\
\hline 6 & $\begin{array}{l}{\left[\mathrm{Dy}\left(\mathrm{L}^{2}\right)_{2}\left(\mathrm{H}_{2} \mathrm{O}\right)_{5}\right]_{2} \cdot \mathrm{Br}_{6}} \\
2 \mathrm{~L}^{2} \cdot 2 \mathrm{H}_{2} \mathrm{O}\end{array}$ & 177.82 & 2.221 & 2.354 & $\begin{array}{c}556 \\
(0 \mathrm{Oe})\end{array}$ & $9.33 \times 10^{-12}$ & {$\left[{ }^{27}\right]$} \\
\hline 7 & $\begin{array}{l}{\left[\mathrm{Dy}\left(\mathrm{Cy}_{3} \mathrm{PO}\right)_{2}\left(\mathrm{H}_{2} \mathrm{O}\right)_{5}\right] \mathrm{Br}_{3}} \\
2\left(\mathrm{Cy}_{3} \mathrm{PO}\right) \cdot 2 \mathrm{H}_{2} \mathrm{O} \cdot 2 \mathrm{EtOH}\end{array}$ & 179.04 & 2.200 & 2.352 & $\begin{array}{c}543 \\
(0 \mathrm{Oe})\end{array}$ & $2.0 \times 10^{-11}$ & {$\left[{ }^{28}\right]$} \\
\hline
\end{tabular}




\begin{tabular}{|c|c|c|c|c|c|c|c|}
\hline 9 & 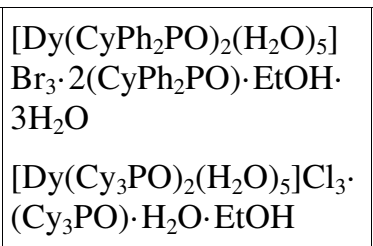 & 175.79 & $\begin{array}{l}2.217 \\
2.219\end{array}$ & $\begin{array}{l}2.364 \\
2.359\end{array}$ & $\begin{array}{c}508 \\
(0 \mathrm{Oe}) \\
\\
472 \\
(0 \mathrm{Oe})\end{array}$ & $8.7 \times 10^{-12}$ & {$\left[{ }^{29}\right]$} \\
\hline 10 & {$\left[(\mathrm{NCN}) \mathrm{DyCl}_{2}(\mathrm{THF})_{2}\right]$} & 176.50 & 2.596 & $\begin{array}{c}2.448 / 2.668 \\
2.393(\mathrm{Dy}-\mathrm{C})\end{array}$ & $\begin{array}{c}335 \\
(0 \mathrm{Oe})\end{array}$ & $6 \times 10^{-10}$ & {$\left[{ }^{30}\right]$} \\
\hline 11 & {$\left[\mathrm{DyCl}_{2}(\mathrm{THF})_{5}\right]\left[\mathrm{BPh}_{4}\right]$} & 179.68 & 2.577 & 2.390 & $\begin{array}{l}80.6 \\
(0 \mathrm{Oe})\end{array}$ & $4.1 \times 10^{-10}$ & {$\left[{ }^{31}\right]$} \\
\hline 12 & $\begin{array}{l}{\left[\mathrm{Dy}(\mathrm{Bpen}) \mathrm{Cl}\left(\mathrm{OPhCl}_{2} \mathrm{NO}\right.\right.} \\
\left.2)_{2}\right]\end{array}$ & 165.60 & 2.174 & $2.523 / 2.616$ & $\begin{array}{c}86 \\
(1 \mathrm{kOe})\end{array}$ & $4.65 \times 10^{-7}$ & {$\left[{ }^{32}\right]$} \\
\hline 13 & {$\left[\left(\mathrm{H}_{2} \mathrm{~L}^{3}\right) \mathrm{Y}_{0.94} \mathrm{Dy}_{0.06} \mathrm{Cl}_{2}\right]$} & 166.32 & 5.643 & $2.264 / 2.444$ & $\begin{array}{c}70 \\
(0.5 \mathrm{kOe})\end{array}$ & $1.9 \times 10^{-6}$ & {$\left[{ }^{17}\right]$} \\
\hline 14 & {$\left[\left(\mathrm{~L}^{4}\right) \mathrm{Dy}\left(\mathrm{Cy}_{3} \mathrm{PO}\right) \mathrm{Cl}\right]$} & 169.62 & $2.237 / 2.625$ & $2.265 / 2.458$ & $\begin{array}{c}204 \\
(1 \mathrm{kOe})\end{array}$ & $6.0 \times 10^{-9}$ & $\begin{array}{l}\text { This } \\
\text { work }\end{array}$ \\
\hline 15 & {$\left[\left(\mathrm{~L}^{4}\right) \mathrm{Dy}\left(\mathrm{Ph}_{3} \mathrm{PO}\right) \mathrm{Cl}\right]$} & 174.07 & $2.276 / 2.623$ & $2.283 / 2.460$ & $\begin{array}{c}241 \\
(1.5 \mathrm{kOe})\end{array}$ & $2.3 \times 10^{-10}$ & $\begin{array}{l}\text { This } \\
\text { work }\end{array}$ \\
\hline
\end{tabular}

methylpyridyl)ethylenediamine); $\quad \mathrm{NCN}: \quad\left[2,6-\left(2,6-\mathrm{C}_{6} \mathrm{H}_{3} \mathrm{R}_{2} \mathrm{~N}_{5} \mathrm{CH}\right)_{2} \mathrm{C}_{6} \mathrm{H}_{3}\right]^{-} ; \quad$ Bpen: $\quad \mathrm{N}, \mathrm{N}^{\prime}-\mathrm{bis}(2-$ methylenepyridinyl)ethylenediamine; $\quad \mathrm{H}_{4} \mathrm{~L}^{3}: \quad$ 2,6-diacetylpyridine bis-salicylhydrazone; $\mathrm{H}_{2} \mathrm{~L}^{4}: \quad 2,6-$ diacetylpyridine bis-benzoylhydrazone

\section{Computational study}

In order to rationalize the experimentally observed magnetization relaxation, we have performed $a b$ initio CASSCF/RASSI+SO/SINGLE_ANISO calculations ${ }^{23}$ on the X-ray structures of complexes 2-5 and the previously reported complex $6^{17}$ in which both the axial positions were occupied by the $\mathrm{Cl}^{-}$ligands. The X-ray analysis revealed that complexes $\mathbf{2}$ and 5 consist of two molecules in the asymmetric unit and we have performed our calculations on the one molecule for each of the complexes. 

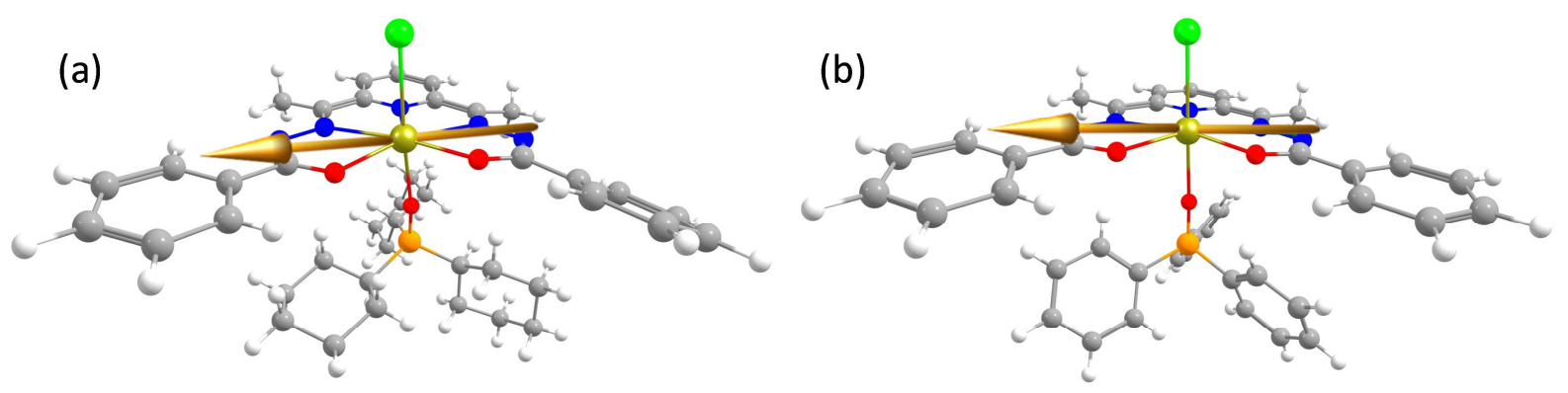

(c)

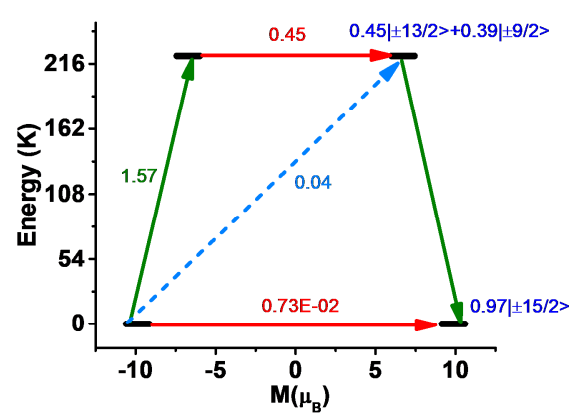

(b)

(d)

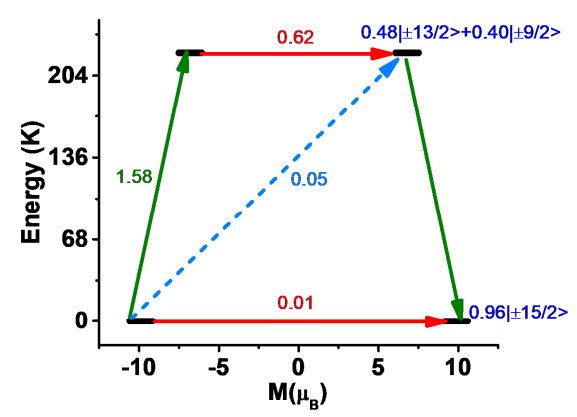

Figure 5. Orientation of the anisotropy axis of Dy(III) ion in complex 3 (a) and 4 (b). (c) and (d) represent the plausible relaxation mechanism for $\mathbf{3}$ and $\mathbf{4}$ respectively. The red arrows show the QTM and TA-QTM via ground and higher excited KD respectively. The sky dotted arrows show the Orbach process for the relaxation. The green arrows show the possible mechanism of magnetic relaxation. The blue characters imply the $\mathrm{m}_{\mathrm{J}}$ composition of the KDs.

Table 2. The computed energy and the associated g-tensors of the low lying KDs generated from ${ }^{6} \mathrm{H}_{15 / 2}$ state of complexes $\mathbf{3}, \mathbf{4}$ and $\mathbf{6}$.

\begin{tabular}{|l|l|l|l|l|}
\hline Energy (K) & $\mathbf{g}_{\mathbf{x}}$ & $\mathbf{g}_{\mathbf{y}}$ & $\mathbf{g}_{\mathrm{z}}$ & $\begin{array}{l}\text { The angle of } \mathbf{g}_{\mathrm{zz}} \text { axis between } \\
\text { the ground and higher excited } \\
\left.\text { KDs }{ }^{\circ}\right)\end{array}$ \\
\hline Complex 3 & \multicolumn{5}{l|}{} \\
\hline 0.0 & 0.013 & 0.030 & 19.741 & \\
\hline 222.6 & 0.910 & 1.684 & 13.977 & 16.2 \\
\hline 277.1 & 0.661 & 3.360 & 11.281 & 19.3 \\
\hline 334.9 & 0.044 & 1.050 & 13.447 & 87.8 \\
\hline 516.4 & 1.005 & 3.829 & 12.313 & 3.6 \\
\hline 599.6 & 2.148 & 5.995 & 13.311 & 92.5 \\
\hline 700.0 & 0.467 & 1.645 & 12.249 & 90.7 \\
\hline 903.6 & 0.145 & 0.743 & 17.531 & 90.4 \\
\hline Complex 4 & 0.020 & 0.041 & 19.734 & \\
\hline 0.0 & 0.954 & 2.781 & 13.614 & 3.7 \\
\hline 222.9 & 0.627 & 1.875 & 11.962 & 6.0 \\
\hline 284.1 &
\end{tabular}




\begin{tabular}{|l|l|l|l|l|}
\hline 398.2 & 1.326 & 1.612 & 16.936 & 88.6 \\
\hline 518.3 & 0.969 & 4.094 & 12.524 & 16.4 \\
\hline 624.5 & 11.040 & 6.990 & 1.617 & 89.9 \\
\hline 724.2 & 1.384 & 3.050 & 11.564 & 91.1 \\
\hline 903.2 & 0.108 & 0.870 & 17.209 & 90.1 \\
\hline Complex 6 & 0.009 & 0.016 & 19.741 & \\
\hline 0.0 & 0.454 & 1.287 & 14.174 & 0.0 \\
\hline 211.0 & 0.683 & 0.816 & 12.236 & 0.0 \\
\hline 281.1 & 1.955 & 3.683 & 11.188 & 90.0 \\
\hline 509.2 & 0.010 & 2.340 & 16.111 & 90.0 \\
\hline 635.5 & 1.061 & 3.553 & 10.520 & 90.0 \\
\hline 704.3 & 3.445 & 5.293 & 8.380 & 90.0 \\
\hline 829.9 & 1.253 & 1.728 & 15.285 & 90.0 \\
\hline 942.3 & & &
\end{tabular}

(a)

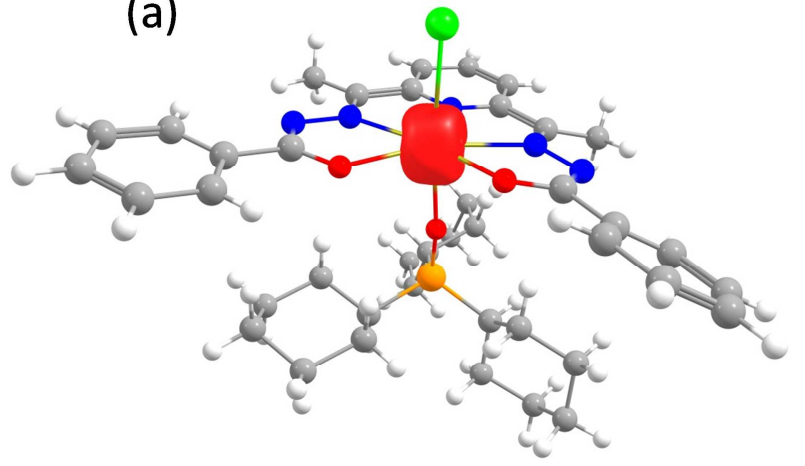

(b)

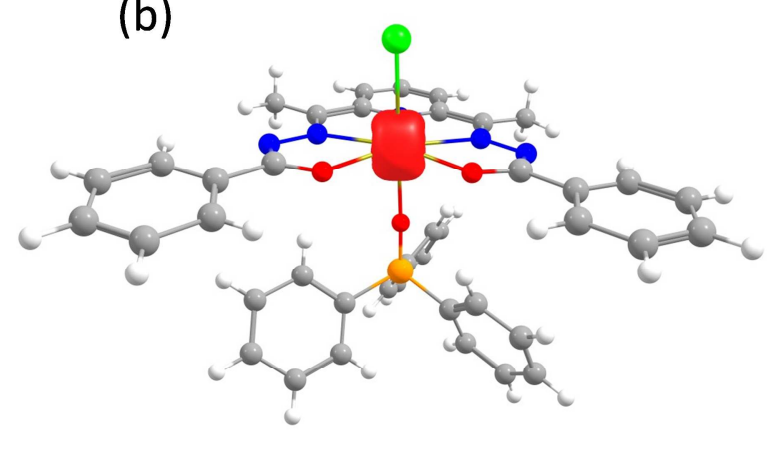

Figure 6. (a) The beta electron density of complex 3. (b) The beta electron density of complex 4. Colour code: Dy-yellow, Cl-green, P-violet, O-red, N-blue, C-grey, H-white.

The computed energy of the eight low lying KDs generated from ${ }^{6} \mathrm{H}_{15 / 2}$ state spans from zero to $903 \mathrm{~K}$ in complexes 3 and 4 and $942 \mathrm{~K}$ in complex 6 (Table 2). The $\mathrm{g}$ tensors; $\mathrm{g}_{\mathrm{x}} \approx \mathrm{g}_{\mathrm{y}} \approx 0$ and $\mathrm{g}_{\mathrm{z}} \approx 20$ for complexes $\mathbf{3}, \mathbf{4}$ and $\mathbf{6}$ demonstrate the Ising behavior of Dy(III) ion in these complexes. The $\mathrm{g}_{\mathrm{zz}}$ axis of ground $\mathrm{KD}$ is found to be lying on the equatorial plane due to the strong crystal field generated from the equatorial ligand (Figure 5 and S14). We have plotted the beta electron density of Dy in complexes 3, 4 and 6 using the procedure introduced by Ruiz and coworkers. ${ }^{33}$ Since the beta electron density is found to orient along the axial $\mathrm{Cl}-$ Dy-O bond ( $\mathrm{Cl}-\mathrm{Dy}-\mathrm{Cl}$ bond in $\mathbf{6})$, the $\mathrm{g}_{\mathrm{zz}}$ anisotropy axis is oriented along the perpendicular direction of it to minimize the electrostatic repulsion (Figure 6). The large thermally assisted 
quantum tunneling (TA-QTM) value of $0.41,0.64$ and $0.24 \mu_{B}$ in the first excited KDs suggest the relaxation will occur ideally through the first excited state KD (Figure 5 and S14). This suggests $U_{\text {cal }}$ value of 222.6, 222.9 and $211.0 \mathrm{~K}$ for complexes $\mathbf{3}, \mathbf{4}$ and $\mathbf{6}$ respectively. These values are consistent with the estimate obtained from the experiments except for $\mathbf{6}$ where $\mathrm{U}_{\text {cal }}$ values are overestimated (for $3208 \mathrm{~K}, 4241 \mathrm{~K}$ and $670 \mathrm{~K}$ ). We have also analyzed the composition of the computed wave function to get more insight about the extent of mixing of the $\mathrm{m}_{\mathrm{J}}$ levels. The ground $\mathrm{KD}$ is found to be consist of $\mathrm{m}_{\mathrm{J}}= \pm 15 / 2(\approx 97 \%)$ with the negligible $(\approx 0.02 \%)$ mixing with $\mathrm{m}_{\mathrm{J}}= \pm 11 / 2$ states. The strong mixing in the first excited KD leads to very large TA-QTM which forces the complex to relax via this state.

The $a b$ initio computed energy barrier for the magnetization reversal does not affect significantly when one $\mathrm{Cl}^{-}$ion in the axial position (complex 6) is replaced by the neutral $\mathrm{Cy}_{3} \mathrm{PO}$ or $\mathrm{Ph}_{3} \mathrm{PO}$ ligand (complexes 3 and 4 respectively). The energy spectrum depends on the ligand field generated from the equatorial ligands which is found to be same in all the complexes. We have analyzed the LoProp charges to get more insight into the axiality of the three complexes. The LoProp charge of the axial oxygen atoms is found to be larger than the equatorial nitrogen and oxygen atoms in $\mathbf{3}$ and $\mathbf{4}$ (Table S9 and Figure S15). More importantly, the ratio of the av. axial/equatorial LoProp charges is found to be almost same in the complexes $\mathbf{3}$ and $\mathbf{4}$ which is consistent with similar $\mathrm{U}_{\mathrm{cal}}$ values estimated in these complexes. The LoProp charge of the axial chlorine atoms and equatorial oxygen atoms is found to be very close in $\mathbf{6}$ which imply the less axial nature of this complex compared to $\mathbf{3}$ and 4. However the av. axial/equatorial LoProp charge $>1.7$ implies significant axiality in this complex.

The crystal field parameter of the three complexes has been estimated using the Steven formalism $\left(\widehat{H}_{C F}=\sum \sum_{k=-q}^{+q} B_{k}^{q} \tilde{O}_{k}^{q}\right.$, where $B_{k}^{q}$ and $\widetilde{O}_{k}^{q}$ is computed crystal field parameter and 
Stevens operator respectively) as implemented in SINGLE_ANISO suite to get more insight on the relaxation mechanism. The axial crystal field parameter $B_{2}^{0}$ is found to be larger in 4 compare to $\mathbf{3}$ implies the stronger axiality in $\mathbf{4}$ which agrees well with the $\mathrm{U}_{\text {eff }}$ value (Table S10). However the $B_{2}^{2}$ value in complex 6 is found to be similar implies lower axiality here compare to 3 and $\mathbf{4}$.

Furthermore, we have modeled the complex 3a, 4a and 6a (where the equatorial ligand has been removed) from complexes 3,4 and $\mathbf{6}$ respectively to achieve the axial limit in each of these complexes. The anisotropy axis is found to be oriented along the $\mathrm{Cl}-\mathrm{Dy}-\mathrm{O}$ bond due to the absence of equatorial ligand field (Figure S16). The beta electron density is found to be oblate in nature and the $\mathrm{g}_{\mathrm{zz}}$ axis is oriented along the axial $\mathrm{Cl}-\mathrm{Dy}-\mathrm{O}$ bond $(\mathrm{Cl}-\mathrm{Dy}-\mathrm{Cl}$ bond in 6) to minimize the electrostatic repulsion (Figure 7). The $a b$ initio calculations on these models reveal that the energy splitting of the eight KDs generated from ${ }^{6} \mathrm{H}_{15 / 2}$ state raises to 2864, 2787 and $2616 \mathrm{~K}$ for 3a, 4a and 6a respectively (Table S11). Absence of equatorial ligand field leads to higher LoProp charge in the Dy center and metal coordinated oxygen atoms revealing the axial limit that can be achieved in these set of complexes (Table S12). It is also reflected in the computed crystal field parameter in which larger $B_{2}^{0}$ value is found compare to original complexes (Table S13). The magnetization relaxation is found to occur via fourth excited $\mathrm{KD}$ due to the strong transverse anisotropy which leads to $\mathrm{U}_{\text {cal }}$ value of 2540, 2471 and $2248 \mathrm{~K}$ in 3a, 4a and 6a respectively (Figure S17). 
(a)

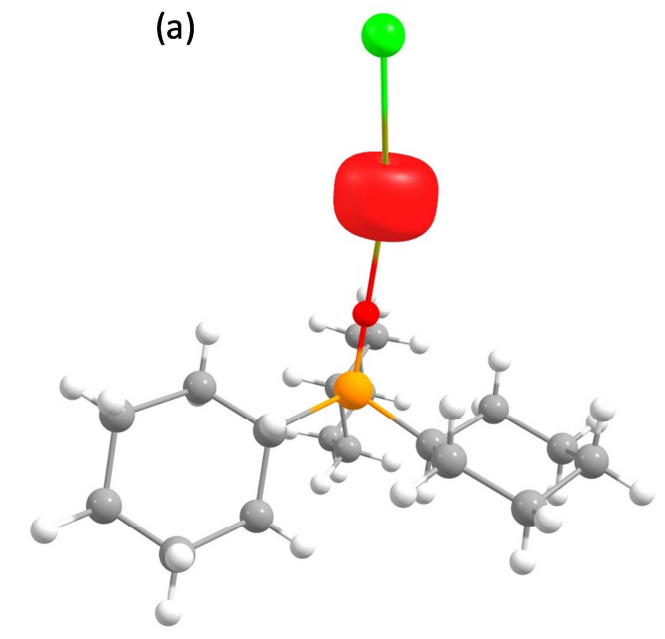

(b)

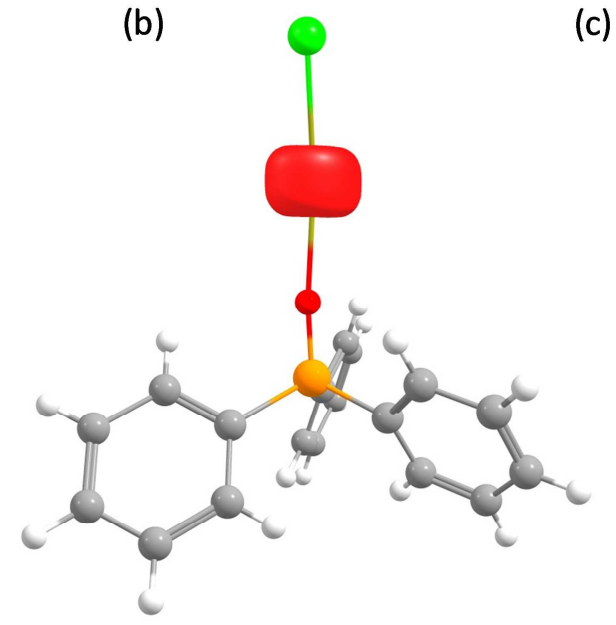

(c)

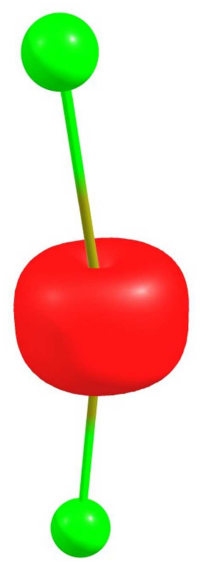

Figure 7. (a) The beta electron (spin-down) density of model 3a. (b) The beta electron density of model 4a. (c) The beta electron density of model 6a. Colour code: Dy-yellow, Clgreen, P-violet, O-red, N-blue, C-grey, H-white.

In the case of complex 2 , a large tunnel splitting $\left(\Delta_{\text {tun }}\right)$ of $2.26 \mathrm{~cm}^{-1}$ is found between the two pseudo ground KDs which triggers the magnetization relaxation via the ground state (Table S14). The ground state anisotropy axis is found to be lying on the equatorial plane due to the strong equatorial ligand field (Figure S18). In case of complex 5 the computed large QTM value of $0.22 \mu_{B}$ between the ground state $\mathrm{KD}$ also suggests the relaxation via ground state which is supported by no out-of-phase signals in ac susceptibility (Figure S18 and Table S15).

\section{Summary}

Mononuclear $4 \mathrm{f}$ complexes $\left(\mathrm{Gd}^{\mathrm{III}}, \mathrm{Dy}^{\mathrm{III}}, \mathrm{Er}^{\mathrm{III}}\right.$ and $\left.\mathrm{Tb}^{\mathrm{III}}\right)$ have been assembled using a multifunctional chelating ligand. The ligand enforces a pentagonal equatorial architecture around the metal ion. The two axial sites are taken up by a chloride and a phosphine oxide ligand. Thus, the overall coordination geometry around the lanthanide metal ion is distorted pentagonal bipyramidal. Magnteic studies on these complexes reveal that the Dy ${ }^{\mathrm{III}}$ analogues 
show a slow relaxation of magnetization under the presence of small DC fields. A large tunneling gap between the ground as well as consequent excited non-Kramers doublets of $\mathrm{Tb}^{\mathrm{III}}$ and a very high quantum tunneling between the ground state Kramers doublets in the $\mathrm{Er}^{\mathrm{III}}$ complex prevents these complexes from revealing a single-ion magnet behavior. The strategy adopted in the present instance of using a rigid ligand that enforces a pentagonal equatorial plane around the lanthanide ion is clearly effective in enabling the designed assembly of single-ion magnets. An improvement in this strategy would be to effect modifications in the ligand design to decrease the effective crystal field in the equatorial plane and increase it in the axial sites. We are currently examining these possibilities.

\section{Acknowledgements}

V. C. is thankful to the Department of Science and Technology, New Delhi, India, for a National J. C. Bose Fellowship. P. K. is thankful to National Institute of Science Education and Research, Bhubaneswar and Tata Institute of Fundamental Research, Hyderabad for doctoral and post-doctoral fellowships respectively. N.A is thankful to Tata Institute of Fundamental Research, Hyderabad for a post-doctoral fellowship. S. D. thanks UGC for SRF fellowship. GR would like to acknowledge SERB for funding (CRG/2018/000430).

\section{Supporting Information}

CCDC 1989266 (1), 1989267(2), 1989268(3), 1989270(4), 1989271(5) contain crystallographic supplementary data for this paper. These data can be obtained free of charge from The Cambridge Crystallographic Data Centre via www.ccdc.cam.ac.uk/data request/cif.

X-ray crystallographic table of complexes 1-5; molecular structures of complexes 1, 2, 4 and 5: crystal packing diagrams of $\mathbf{1}$ and 4 . table of bond distances and angles; table of continuous shape measures calculations; powder X-ray diffraction pattern of 3'. details of magnetic properties of 1-5; details of computaional calculations of complexes 1-5 (PDF). 


\section{References}

1. (a) Robinson, J. R.; Fan, X.; Yadav, J.; Carroll, P. J.; Wooten, A. J.; Pericàs, M. A.; Schelter, E. J.; Walsh, P. J. Air- and Water-Tolerant Rare Earth Guanidinium BINOLate Complexes as Practical Precatalysts in Multifunctional Asymmetric Catalysis. J. Am. Chem. Soc. 2014, 136, 8034-8041; (b) Chen, S.; Yan, D.; Xue, M.; Hong, Y.; Yao, Y.; Shen, Q. Tris(cyclopentadienyl)lanthanide Complexes as Catalysts for Hydroboration Reaction toward Aldehydes and Ketones. Org. Lett. 2017, 19, 3382-3385; (c) Halter, D. P.; Palumbo, C. T.; Ziller, J. W.; Gembicky, M.; Rheingold, A. L.; Evans, W. J.; Meyer, K. Electrocatalytic H2O Reduction with f-Elements: Mechanistic Insight and Overpotential Tuning in a Series of Lanthanide Complexes. J. Am. Chem. Soc. 2018, 140, 2587-2594; (d) Nagae, H.; Aoki, R.; Akutagawa, S.-n.; Kleemann, J.; Tagawa, R.; Schindler, T.; Choi, G.; Spaniol, T. P.; Tsurugi, H.; Okuda, J.; Mashima, K. Lanthanide Complexes Supported by a Trizinc Crown Ether as Catalysts for Alternating Copolymerization of Epoxide and CO2: Telomerization Controlled by Carboxylate Anions. Angew. Chem. Int. Ed. 2018, 57, 2492-2496; (e) Schmidt, B. M.; Pindwal, A.; Venkatesh, A.; Ellern, A.; Rossini, A. J.; Sadow, A. D. Zwitterionic Trivalent (Alkyl)lanthanide Complexes in Ziegler-Type Butadiene Polymerization. ACS Catal. 2019, 9, 827-838.

2. (a) Bünzli, J.-C. G. On the design of highly luminescent lanthanide complexes. Coord. Chem. Rev. 2015, 293-294, 19-47; (b) Hirai, Y.; Nakanishi, T.; Kitagawa, Y.; Fushimi, K.; Seki, T.; Ito, H.; Hasegawa, Y. Luminescent Europium(III) Coordination Zippers Linked with Thiophene-Based Bridges. Angew. Chem. Int. Ed. 2016, 55, 1205912062; (c) Wei, H.; Zhao, Z.; Wei, C.; Yu, G.; Liu, Z.; Zhang, B.; Bian, J.; Bian, Z.; Huang, C. Antiphotobleaching: A Type of Structurally Rigid Chromophore Ready for Constructing Highly Luminescent and Highly Photostable Europium Complexes. Adv. Funct. Mater. 2016, 
26, 2085-2096; (d) Kovacs, D.; Lu, X.; Mészáros, L. S.; Ott, M.; Andres, J.; Borbas, K. E. Photophysics of Coumarin and Carbostyril-Sensitized Luminescent Lanthanide Complexes: Implications for Complex Design in Multiplex Detection. J. Am. Chem. Soc. 2017, 139, 5756-5767; (e) Martinić, I.; Eliseeva, S. V.; Nguyen, T. N.; Pecoraro, V. L.; Petoud, S. NearInfrared Optical Imaging of Necrotic Cells by Photostable Lanthanide-Based Metallacrowns. J. Am. Chem. Soc. 2017, 139, 8388-8391; (f) Xiang, S.; Bao, D.-X.; Wang, J.; Li, Y.-C.; Zhao, X.-Q. Luminescent lanthanide coordination compounds with pyridine-2,6-dicarboxylic acid. J. Lumin. 2017, 186, 273-282; (g) Qiao, Y.; Schelter, E. J. Lanthanide Photocatalysis. Acc. Chem. Res. 2018, 51, 2926-2936; (h) Du, Y.; Jiang, Y.; Sun, T.; Zhao, J.; Huang, B.; Peng, D.; Wang, F. Mechanically Excited Multicolor Luminescence in Lanthanide Ions. Adv. Mater. 2019, 31, 1807062.

3. (a) Strnat, K.; Hoffer, G.; Olson, J.; Ostertag, W.; Becker, J. J. A Family of New Cobalt-Base Permanent Magnet Materials. J. Appl. Phys. 1967, 38, 1001-1002; (b) Vincent, R.; Klyatskaya, S.; Ruben, M.; Wernsdorfer, W.; Balestro, F. Electronic read-out of a single nuclear spin using a molecular spin transistor. Nature 2012, 488, 357-360; (c) Woodruff, D. N.; Winpenny, R. E. P.; Layfield, R. A. Lanthanide Single-Molecule Magnets. Chem. Rev. 2013, 113, 5110-5148; (d) Kiefl, E.; Mannini, M.; Bernot, K.; Yi, X.; Amato, A.; Leviant, T.; Magnani, A.; Prokscha, T.; Suter, A.; Sessoli, R.; Salman, Z. Robust Magnetic Properties of a Sublimable Single-Molecule Magnet. ACS Nano 2016, 10, 5663-5669; (e) Zhu, Z.; Guo, M.; Li, X.-L.; Tang, J. Molecular magnetism of lanthanide: Advances and perspectives. Coord. Chem. Rev. 2019, 378, 350-364.

4. (a) Coutinho, J. T.; Monteiro, B.; Pereira, L. C. J. In Lanthanide-Based Multifunctional Materials; Martín-Ramos, P., Ramos Silva, M., Ed.; Elsevier: 2018; pp 195231; (b) Dey, A.; Kalita, P.; Chandrasekhar, V. Lanthanide(III)-Based Single-Ion Magnets. 
ACS Omega 2018, 3, 9462-9475; (c) Lu, J.; Guo, M.; Tang, J. Recent Developments in Lanthanide Single-Molecule Magnets. Chem. Asian J. 2017, 12, 2772-2779; (d) Kahn, O. Molecular Magnetism. Willey VCH: 1993.

5. (a) Meihaus, K. R.; Long, J. R. Actinide-based single-molecule magnets. Dalton Trans. 2015, 44, 2517-2528; (b) Future Directions for Transuranic Single Molecule Magnets. Inorganics 2018, 6, 26; (c) Coutinho, J. T.; Perfetti, M.; Baldovi, J. J.; Antunes, M. A.; Hallmen, P. P.; Bamberger, H.; Crassee, I.; Orlita, M.; Almeida, M.; van Slageren, J.; Pereira, L. C. J. Spectroscopic Determination of the Electronic Structure of a Uranium Single-Ion Magnet. Chem. Eur. J. 2019, 25, 1758-1766; (d) King, D. M.; Cleaves, P. A.; Wooles, A. J.; Gardner, B. M.; Chilton, N. F.; Tuna, F.; Lewis, W.; McInnes, E. J. L.; Liddle, S. T. Molecular and electronic structure of terminal and alkali metal-capped uranium(V) nitride complexes. Nat. Commun. 2016, 7, 13773; (e) Chatelain, L.; Tuna, F.; Pécaut, J.; Mazzanti, M. A zig-zag uranyl(v)-Mn(ii) single chain magnet with a high relaxation barrier. Chem. Commun. 2015, 51, 11309-11312.

6. (a) Layfield, R. A.; Murugesu, M. Lanthanides and Actinides in Molecular Magnetism. Wiley-VCH Verlag GmbH \& Co. KGaA 2015; (b) Gao, S. E. Molecular Nanomagnets and Related Phenomena. Springer-Verlag Berlin Heidelberg: 2015; (c) Gatteschi, D.; Sessoli, R.; Villain, J. Molecular Nanomagnets. 2006.

7. Benelli, C.; Gatteschi, D. Introduction to Molecular Magnetism: From Transition Metals to Lanthanides. Wiley-VCH.

8. Bartolomé, E.; Arauzo, A.; Luzón, J.; Bartolomé, J.; Bartolomé, F. In Handbook of Magnetic Materials; Brück, E., Ed.; Elsevier: 2017; Vol. 26, pp 1-289. 
9. Ishikawa, N.; Sugita, M.; Ishikawa, T.; Koshihara, S.-y.; Kaizu, Y. Lanthanide Double-Decker Complexes Functioning as Magnets at the Single-Molecular Level. J. Am. Chem. Soc. 2003, 125, 8694-8695.

10. Cotton, S. A. Lanthanides and Actinides. Macmillan, London: 1991.

11. (a) Liddle, S. T.; van Slageren, J. Improving f-element single molecule magnets. Chem. Soc. Rev. 2015, 44, 6655-6669; (b) Chilton, N. F. Design Criteria for HighTemperature Single-Molecule Magnets. Inorg. Chem. 2015, 54, 2097-2099; (c) Ungur, L.; Chibotaru, L. F. Strategies toward High-Temperature Lanthanide-Based Single-Molecule Magnets. Inorg. Chem. 2016, 55, 10043-10056; (d) Liu, J.-L.; Chen, Y.-C.; Tong, M.-L. Symmetry strategies for high performance lanthanide-based single-molecule magnets. Chem. Soc. Rev. 2018, 47, 2431-2453.

12. (a) Day, B. M.; Guo, F.-S.; Layfield, R. A. Cyclopentadienyl Ligands in Lanthanide Single-Molecule Magnets: One Ring To Rule Them All? Acc. Chem. Res. 2018, 51, 18801889; (b) Harriman, K. L. M.; Murugesu, M. An Organolanthanide Building Block Approach to Single-Molecule Magnets. Acc. Chem. Res. 2016, 49, 1158-1167; (c) Bar, A. K.; Kalita, P.; Singh, M. K.; Rajaraman, G.; Chandrasekhar, V. Low-coordinate mononuclear lanthanide complexes as molecular nanomagnets. Coord. Chem. Rev. 2018, 367, 163-216.

13. (a) Guo, F.-S.; Day, B. M.; Chen, Y.-C.; Tong, M.-L.; Mansikkamäki, A.; Layfield, R. A. Magnetic hysteresis up to 80 kelvin in a dysprosium metallocene single-molecule magnet. Science 2018, 362, 1400-1403; (b) Goodwin, C. A. P.; Ortu, F.; Reta, D.; Chilton, N. F.; Mills, D. P. Molecular magnetic hysteresis at 60 kelvin in dysprosocenium. Nature 2017, 548, 439-442; (c) Guo, F.-S.; Day, B. M.; Chen, Y.-C.; Tong, M.-L.; Mansikkamäki, A.; 
Layfield, R. A. A Dysprosium Metallocene Single-Molecule Magnet Functioning at the Axial Limit. Angew. Chem. Int. Ed. 2017, 56, 11445-11449.

14. Rinehart, J. D.; Long, J. R. Exploiting Single-Ion Anisotropy in the Design of fElement Single-Molecule Magnets. Chem. Sci. 2011, 2, 2078-2085.

15. (a) Zhang, P.; Zhang, L.; Wang, C.; Xue, S.; Lin, S.-Y.; Tang, J. Equatorially Coordinated Lanthanide Single Ion Magnets. J. Am. Chem. Soc. 2014, 136, 4484-4487; (b) Sun, W.-B.; Yan, P.-F.; Jiang, S.-D.; Wang, B.-W.; Zhang, Y.-Q.; Li, H.-F.; Chen, P.; Wang, Z.-M.; Gao, S. High symmetry or low symmetry, that is the question - high performance Dy(iii) single-ion magnets by electrostatic potential design. Chem. Sci. 2016, 7, 684-691; (c) Chen, Y.-C.; Liu, J.-L.; Wernsdorfer, W.; Liu, D.; Chibotaru, L. F.; Chen, X.-M.; Tong, M.L. Hyperfine-Interaction-Driven Suppression of Quantum Tunneling at Zero Field in a Holmium(III) Single-Ion Magnet. Angew. Chem. Int. Ed. 2017, 56, 4996-5000; (d) Gupta, S. K.; Murugavel, R. Enriching lanthanide single-ion magnetism through symmetry and axiality. Chem. Commun. 2018, 54, 3685-3696.

16. (a) Kalita, P.; Acharya, J.; Chandrasekhar, V. Mononuclear pentagonal bipyramidal Ln(III) complexes: Syntheses and magnetic properties. J. Magn. Magn. Mater. 2020, 498, 166098; (b) Gupta, S. K.; Rajeshkumar, T.; Rajaraman, G.; Murugavel, R. An air-stable Dy(iii) single-ion magnet with high anisotropy barrier and blocking temperature. Chem. Sci. 2016, 7, 5181-5191; (c) Liu, J.; Chen, Y.-C.; Liu, J.-L.; Vieru, V.; Ungur, L.; Jia, J.-H.; Chibotaru, L. F.; Lan, Y.; Wernsdorfer, W.; Gao, S.; Chen, X.-M.; Tong, M.-L. A Stable Pentagonal Bipyramidal Dy(III) Single-Ion Magnet with a Record Magnetization Reversal Barrier over 1000 K. J. Am. Chem. Soc. 2016, 138, 5441-5450; (d) Jiang, Z.; Sun, L.; Yang, Q.; Yin, B.; Ke, H.; Han, J.; Wei, Q.; Xie, G.; Chen, S. Excess axial electrostatic repulsion as 
a criterion for pentagonal bipyramidal DyIII single-ion magnets with high Ueff and TB. $J$. Mater. Chem. C 2018, 6, 4273-4280; (e) Ding, Y.-S.; Chilton, N. F.; Winpenny, R. E. P.; Zheng, Y.-Z. On Approaching the Limit of Molecular Magnetic Anisotropy: A Near-Perfect Pentagonal Bipyramidal Dysprosium(III) Single-Molecule Magnet. Angew. Chem. Int. Ed. 2016, 55, 16071-16074.

17. Bar, A. K.; Kalita, P.; Sutter, J.-P.; Chandrasekhar, V. Pentagonal-Bipyramid Ln(III) Complexes Exhibiting Single-Ion-Magnet Behavior: A Rational Synthetic Approach for a Rigid Equatorial Plane. Inorg. Chem. 2018, 57, 2398-2401.

18. Pelizzi, C.; Pelizzi, G. Investigation into aroylhydrazones as chelating agents. Synthesis and structural characterization of a tin(IV) complex with 2,6-diacetylpyridine bis(salicyloylhydrazone). J. Chem. Soc., Dalton Trans. 1980, 1970-1973.

19. Sheldrick, G. M. SHELXT-Integrated Space-Group and Crystal-Structure Determination. Acta Crystallogr., Sect. A: Found. Adv. 2015, 71, 3-8.

20. Sheldrick, G. M. Crystal Structure Refinement with SHELXL. Acta Crystallogr., Sec. C: Struct. Chem. 2015, 71, 3-8.

21. Dolomanov, O. V.; Bourhis, L. J.; Gildea, R. J.; Howard, J. A. K.; Puschmann, H. OLEX2: a complete structure solution, refinement and analysis program. J. Appl. Crystallogr. 2009, 42, 339-341.

22. Brandenburg, K.; Putz, H. DIAMOND, version 3.2; Crystal Impact GbR: Bonn, Germany, 1997-2014. 
23. Aquilante, F.; Autschbach, J.; Carlson, R. K.; Chibotaru, L. F.; Delcey, M. G.; De Vico, L.; Fdez. Galván, I.; Ferré, N.; Frutos, L. M.; Gagliardi, L.; Garavelli, M.; Giussani, A.; Hoyer, C. E.; Li Manni, G.; Lischka, H.; Ma, D.; Malmqvist, P. Å.; Müller, T.; Nenov, A.; Olivucci, M.; Pedersen, T. B.; Peng, D.; Plasser, F.; Pritchard, B.; Reiher, M.; Rivalta, I.; Schapiro, I.; Segarra-Martí, J.; Stenrup, M.; Truhlar, D. G.; Ungur, L.; Valentini, A.; Vancoillie, S.; Veryazov, V.; Vysotskiy, V. P.; Weingart, O.; Zapata, F.; Lindh, R. Molcas 8: New capabilities for multiconfigurational quantum chemical calculations across the periodic table. J. Comput. Chem. 2016, 37, 506-541.

24. Reiher, M. Relativistic Douglas-Kroll-Hess theory. Wiley Interdiscip. Rev. Comput. Mol. Sci. 2012, 2, 139-149.

25. (a) SHAPE: Continuous Shape Measures calculation, 2.1; Electronic Structure Group, Universitat de Barcelona, Spain, 2013; (b) Cirera, J.; Ruiz, E.; Alvarez, S. Continuous Shape Measures as a Stereochemical Tool in Organometallic Chemistry. Organometallics 2005, 24, $1556-1562$.

26. Ding, Y.-S.; Yu, K.-X.; Reta, D.; Ortu, F.; Winpenny, R. E. P.; Zheng, Y.-Z.; Chilton, N. F. Field- and temperature-dependent quantum tunnelling of the magnetisation in a large barrier single-molecule magnet. Nat. Commun. 2018, 9, 3134.

27. Li, L.-L.; Su, H.-D.; Liu, S.; Xu, Y.-C.; Wang, W.-Z. A new air- and moisture-stable pentagonal-bipyramidal DyIII single-ion magnet based on the HMPA ligand. Dalton Trans. 2019, 48, 2213-2219. 
28. Chen, Y.-C.; Liu, J.-L.; Ungur, L.; Liu, J.; Li, Q.-W.; Wang, L.-F.; Ni, Z.-P.; Chibotaru, L. F.; Chen, X.-M.; Tong, M.-L. Symmetry-Supported Magnetic Blocking at 20 K in Pentagonal Bipyramidal Dy(III) Single-Ion Magnets. J. Am. Chem. Soc. 2016, 138, 28292837.

29. Chen, Y.-C.; Liu, J.-L.; Lan, Y.; Zhong, Z.-Q.; Mansikkamäki, A.; Ungur, L.; Li, Q.W.; Jia, J.-H.; Chibotaru, L. F.; Han, J.-B.; Wernsdorfer, W.; Chen, X.-M.; Tong, M.-L. Dynamic Magnetic and Optical Insight into a High Performance Pentagonal Bipyramidal DyIII Single-Ion Magnet. Chem. Eur. J. 2017, 23, 5708-5715.

30. Guo, Y.-N.; Ungur, L.; Granroth, G. E.; Powell, A. K.; Wu, C.; Nagler, S. E.; Tang, J.; Chibotaru, L. F.; Cui, D. An NCN-pincer ligand dysprosium single-ion magnet showing magnetic relaxation via the second excited state. Sci. Rep. 2014, 4, 5471.

31. Long, J.; Selikhov, A. N.; Mamontova, E.; Lyssenko, K. A.; Guari, Y.; Larionova, J.; Trifonov, A. A. Single-molecule magnet behaviour in a Dy(iii) pentagonal bipyramidal complex with a quasi-linear Cl-Dy-Cl sequence. Dalton Trans. 2019, 48, 35-39.

32. Li, M.; Wu, H.; Yang, Q.; Ke, H.; Yin, B.; Shi, Q.; Wang, W.; Wei, Q.; Xie, G.; Chen, S. Experimental and Theoretical Interpretation on the Magnetic Behavior in a Series of Pentagonal-Bipyramidal DyIII Single-Ion Magnets. Chem. Eur. J. 2017, 23, 17775-17787.

33. (a) Aravena, D.; Ruiz, E. Shedding Light on the Single-Molecule Magnet Behavior of Mononuclear DyIII Complexes. Inorg. Chem. 2013, 52, 13770-13778; (b) Norre, M. S.; Gao, C.; Dey, S.; Gupta, S. K.; Borah, A.; Murugavel, R.; Rajaraman, G.; Overgaard, J. HighPressure Crystallographic and Magnetic Studies of Pseudo-D5h Symmetric Dy(III) and 
Ho(III) Single-Molecule Magnets. Inorg. Chem. 2020, 59, 717-729; (c) Dey, S.; Rajaraman, G. In silico design of pseudo D5h actinide based molecular magnets: role of covalency in magnetic anisotropy. J. Chem. Sci. 2019, 131, 124. 


\section{Supporting Information}

Table S1. Crystallographic data and refinement parameters of 1-5.

\begin{tabular}{|c|c|c|c|c|c|}
\hline & 1 & 2 & 3 & 4 & 5 \\
\hline Empirical formula & $\begin{array}{l}\mathrm{C}_{41} \mathrm{H}_{52} \mathrm{Cl}_{1} \mathrm{Gd}_{1} \mathrm{~N}_{5} \mathrm{O}_{3} \mathrm{P} \\
1\end{array}$ & $\begin{array}{l}\mathrm{C}_{84} \mathrm{H}_{116} \mathrm{Cl}_{2} \mathrm{~N}_{12} \mathrm{O}_{8} \mathrm{P}_{2} \mathrm{~Tb} \\
2\end{array}$ & $\begin{array}{l}\mathrm{C}_{90} \mathrm{H}_{124} \mathrm{Cl}_{2} \mathrm{Dy}_{2} \mathrm{~N}_{10} \mathrm{O}_{8} \mathrm{P} \\
2\end{array}$ & $\begin{array}{l}\mathrm{C}_{41} \mathrm{H}_{34} \mathrm{Cl}_{1} \mathrm{Dy}_{1} \mathrm{~N}_{5} \mathrm{O}_{3} \mathrm{P} \\
{ }_{1}\end{array}$ & $\begin{array}{l}\mathrm{C}_{86} \mathrm{H}_{116} \mathrm{Cl}_{2} \mathrm{Er}_{2} \mathrm{~N}_{10} \mathrm{O}_{8} \mathrm{P} \\
2\end{array}$ \\
\hline $\begin{array}{l}\text { Formula weight } \\
\left(\mathrm{gmol}^{-1}\right)\end{array}$ & 886.54 & 1872.56 & 1931.82 & 873.65 & 1885.24 \\
\hline Temperature (K) & $120.00(10)$ & $120.00(10)$ & $120(2) \mathrm{K}$ & $120(2)$ & $120.00(10)$ \\
\hline Crystal system & Monoclinic & Triclinic & Monoclinic & Triclinic & Monoclinic \\
\hline Space group & $P 21 / \mathrm{n}$ & $P-1$ & $P 21 / \mathrm{c}$ & $P-1$ & $P 21 / \mathrm{n}$ \\
\hline Unit cell lengths $(\AA ̊)$ & $\begin{array}{l}\mathrm{a}=20.1164(5) \\
\mathrm{b}=9.6283(2) \\
\mathrm{c}=22.3601(6)\end{array}$ & $\begin{array}{l}\mathrm{a}=10.0872(3) \\
\mathrm{b}=18.3148(5) \\
\mathrm{c}=23.4884(6)\end{array}$ & $\begin{array}{l}\mathrm{a}=18.6952(5) \\
\mathrm{b}=9.9898(3) \\
\mathrm{c}=24.5545(7)\end{array}$ & $\begin{array}{l}\mathrm{a}=8.8046(2) \\
\mathrm{b}=11.5978(2) \\
\mathrm{c}=18.9669(3)\end{array}$ & $\begin{array}{l}a=23.5494(8) \\
b=10.0618(3) \\
c=36.0847(11)\end{array}$ \\
\hline Unit cell angles $\left({ }^{\circ}\right)$ & $\beta=113.594(3)$ & $\begin{array}{l}\alpha=84.704(2) \\
\beta=89.758(2) \\
\gamma=83.504(2)\end{array}$ & $\beta=91.430(2)$ & $\begin{array}{l}\alpha=93.4930(10) \\
\beta=101.8670(10) \\
\gamma=103.418(2)\end{array}$ & $\beta=94.409(3)$ \\
\hline Volume $\left(\AA^{3}\right)$ & $3968.81(19)$ & $4293.0(2)$ & $4584.4(2)$ & $1831.60(6)$ & $8524.9(5)$ \\
\hline $\mathrm{Z}$ & 4 & 2 & 2 & 2 & 8 \\
\hline Density (calculated) & 1.484 & 1.449 & $1.399 \mathrm{mg} / \mathrm{m}^{3}$ & 1.584 & 1.469 \\
\hline Absorption coefficient & 1.823 & 1.794 & $1.769 \mathrm{~mm}^{-1}$ & 2.203 & 2.116 \\
\hline$F(000)$ & 1812.0 & 1924.0 & 1988.0 & 874.0 & 3864.0 \\
\hline Crystal size $(\mathrm{mm})$ & $0.17 \times 0.14 \times 0.1$ & $0.18 \times 0.14 \times 0.07$ & $\begin{array}{l}0.3 \times 0.08 \times 0.01 \\
\mathrm{~mm}^{3}\end{array}$ & $0.34 \times 0.11 \times 0.09$ & $0.21 \times 0.12 \times 0.09$ \\
\hline $\begin{array}{lll}2 \theta & \text { range for data } \\
\text { collection }\left({ }^{\circ}\right) & & \\
\end{array}$ & 5.5 to 58.818 & 5.244 to 49.998 & 5.412 to $57.664^{\circ}$ & 4.884 to 58.042 & 4.892 to 58.068 \\
\hline Reflections collected & 62624 & 91078 & 53867 & 27626 & 96210 \\
\hline Index ranges & $\begin{array}{l}-27 \leq h \leq 24, \\
-11 \leq k \leq 12 \\
-30 \leq 1 \leq 27\end{array}$ & $\begin{array}{l}-11 \leq \mathrm{h} \leq 11, \\
-21 \leq \mathrm{k} \leq 21, \\
-27 \leq \mathrm{I} \leq 27\end{array}$ & $\begin{array}{l}-24 \leq \mathrm{h} \leq 23 \\
-13 \leq \mathrm{k} \leq 8 \\
-33 \leq 1 \leq 30\end{array}$ & $\begin{array}{l}-11 \leq h \leq 9 \\
-15 \leq k \leq 15 \\
-24 \leq 1 \leq 24\end{array}$ & $\begin{array}{l}-30 \leq \mathrm{h} \leq 32 \\
-13 \leq \mathrm{k} \leq 13 \\
-45 \leq \mathrm{I} \leq 44\end{array}$ \\
\hline Independent reflections & $\begin{array}{l}9730\left[R_{\text {int }}=\right. \\
0.0382]\end{array}$ & $\begin{array}{l}15077 \quad\left[R_{\text {int }}=\right. \\
0.0576]\end{array}$ & $\begin{array}{l}10841 \quad\left[R_{\text {int }}=\right. \\
0.0587]\end{array}$ & $\begin{array}{l}8459\left[R_{\text {int }}=\right. \\
0.0448]\end{array}$ & $\begin{array}{l}19876 \quad\left[R_{\text {int }}=\right. \\
0.0840]\end{array}$ \\
\hline $\begin{array}{l}\text { Data/Restrain/Paramete } \\
\text { r }\end{array}$ & $9730 / 0 / 471$ & $15077 / 0 / 999$ & $10841 / 0 / 518$ & $8459 / 0 / 471$ & 19876/0/999 \\
\hline Goodness-of-fit on $\mathrm{F}^{2}$ & 1.031 & 1.159 & 1.040 & 1.055 & 1.026 \\
\hline $\begin{array}{lcr}\text { Final } & R & \text { indices } \\
{[I>2 \text { sigma(I)] }} & \end{array}$ & $\begin{array}{l}R_{1}=0.0228 \\
\mathrm{w} R_{2}=0.0448\end{array}$ & $\begin{array}{l}R_{1}=0.0492 \\
\mathrm{w} R_{2}=0.1197\end{array}$ & $\begin{array}{l}R_{1}=0.0346 \\
\mathrm{w} R_{2}=0.0644\end{array}$ & $\begin{array}{l}R_{1}=0.0293 \\
\mathrm{w} R_{2}=0.0648\end{array}$ & $\begin{array}{l}R_{1}=0.0470 \\
\mathrm{w} R_{2}=0.0936\end{array}$ \\
\hline $\mathrm{R}$ indices (all data) & $\begin{array}{l}R_{1}=0.0289 \\
w R_{2}=0.0465\end{array}$ & $\begin{array}{l}R_{1}=0.0549 \\
w R_{2}=0.1223\end{array}$ & $\begin{array}{l}R_{1}=0.0571 \\
\mathrm{w} R_{2}=0.0704\end{array}$ & $\begin{array}{l}R_{1}=0.0348 \\
\mathrm{w} R_{2}=0.0668\end{array}$ & $\begin{array}{l}R_{1}=0.0898 \\
w R_{2}=0.1079\end{array}$ \\
\hline
\end{tabular}




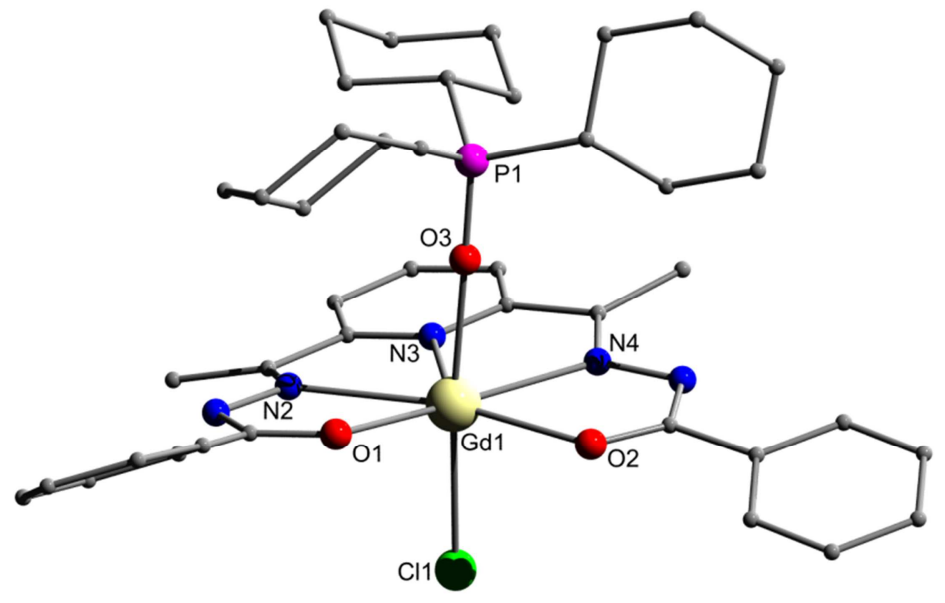

Figure S1. Molecular structure of complex 1. (H-atoms are omitted for clarity)

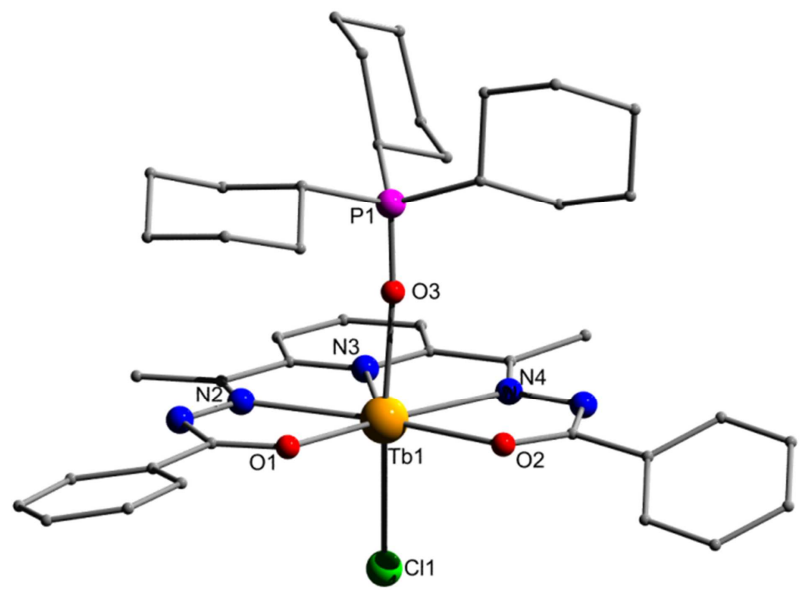

Figure S2. Molecular structure of complex 2. (H-atoms are omitted for clarity)

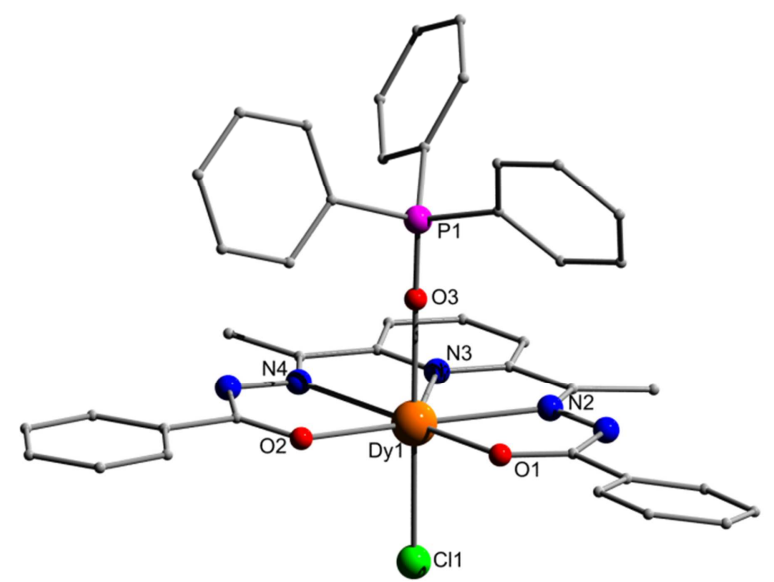

Figure S3. Molecular structure of complex 4. (H-atoms are omitted for clarity) 


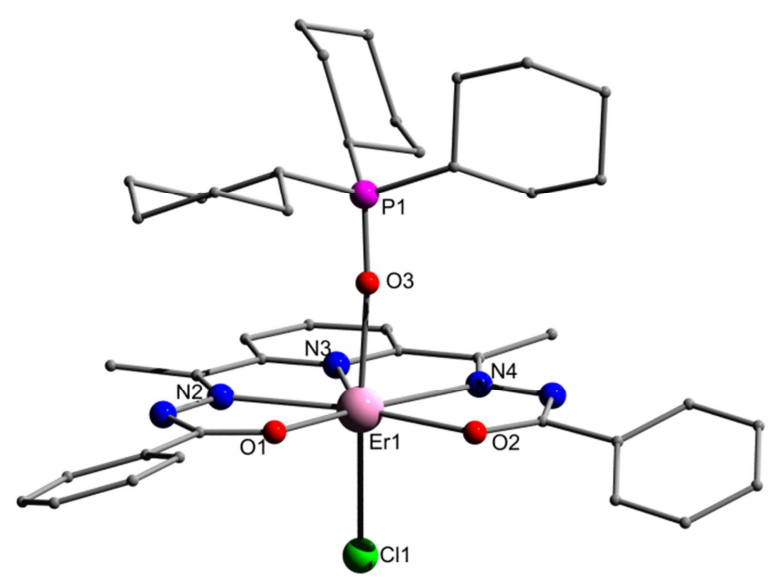

Figure S4. Molecular structure of complex 5. (H-atoms are omitted for clarity)

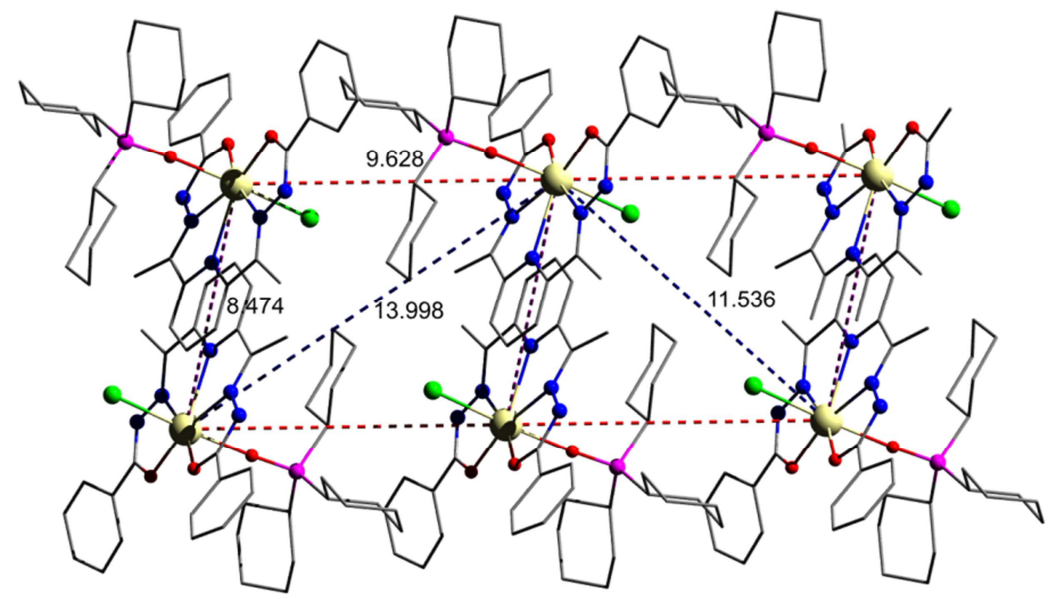

Figure S5. Solid-state packing diagram of complex 1 viewed along the crystallographic $c$ axis. (H-atoms are omitted for clarity)

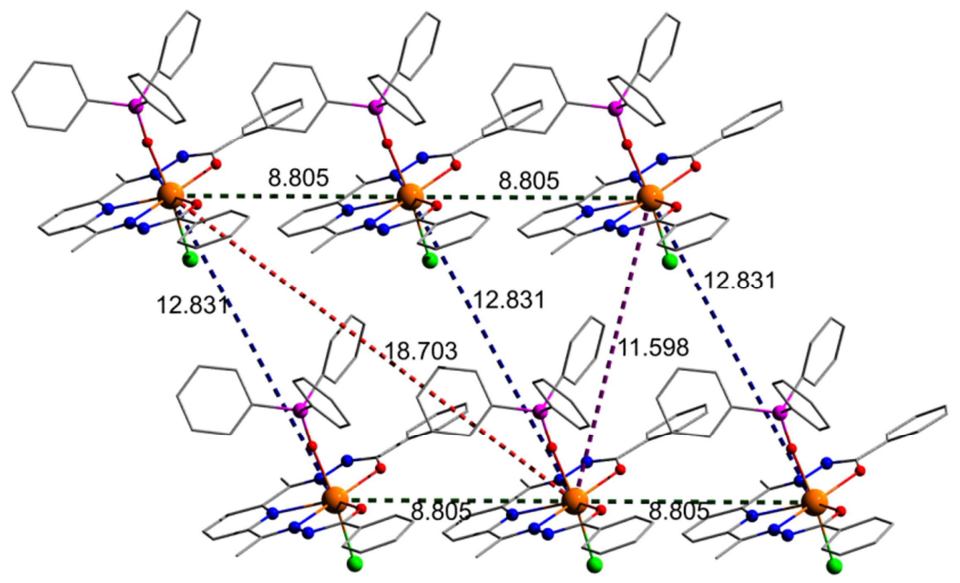

Figure S6. Solid-state packing diagram of complex 4 viewed along the crystallographic $c$ axis (H-atoms are omitted for clarity). 
Table 2. Bond distance and bond angle parameters of complex $\mathbf{3}$.

\begin{tabular}{|c|c|c|c|c|c|}
\hline \multicolumn{2}{|c|}{ Bond distances (Å) } & \multicolumn{4}{|c|}{ Bond angles $\left({ }^{\circ}\right)$} \\
\hline & & O2-Dy1-Cl1 & $93.19(5)$ & O2-Dy1-01 & $100.23(7)$ \\
\hline Dy1-Cl1 & $2.625(8)$ & O2-Dy1-N3 & $130.25(7)$ & O2-Dy1-N2 & $165.17(7)$ \\
\hline Dy1-01 & $2.272(2)$ & O2-Dy1-N4 & $65.59(7)$ & O3-Dy1-Cl1 & $169.62(5)$ \\
\hline Dy1-02 & $2.259(2)$ & O3-Dy1-01 & $92.19(7)$ & O3-Dy1-02 & $90.35(7)$ \\
\hline Dy1-03 & $2.237(2)$ & O3-Dy1-N3 & $84.83(7)$ & O3-Dy1-N2 & $91.41(7)$ \\
\hline Dy1-N3 & $2.462(2)$ & O3-Dy1-N4 & $81.19(7)$ & N3-Dy1-Cl1 & $85.44(6)$ \\
\hline Dy1-N2 & $2.464(2)$ & N3-Dy1-N2 & $64.57(7)$ & N2-Dy1-Cl1 & $87.67(6)$ \\
\hline \multirow[t]{3}{*}{ Dy1-N4 } & $2.448(2)$ & O1-Dy1-Cl1 & $96.78(6)$ & O1-Dy1-N3 & $129.37(7)$ \\
\hline & & O1-Dy1-N2 & $65.00(7)$ & O1-Dy1-N4 & $164.10(7)$ \\
\hline & & N4-Dy1-Cl1 & $91.39(6)$ & N4-Dy1-N3 & $64.74(7)$ \\
\hline
\end{tabular}

Table S3. Continuous shape analysis

\begin{tabular}{|c|c|c|c|c|c|c|c|}
\hline \multirow{2}{*}{ Complex } & \multicolumn{7}{|c|}{ Structure! } \\
\cline { 2 - 8 } & HP-7 & HPY-7 & PBPY-7 & COC-7 & CTPR-7 & JPBPY-7 & JETPY-7 \\
\hline $\mathbf{1}$ & 31.572 & 19.350 & 2.233 & 7.665 & 6.207 & 6.298 & 18.718 \\
\hline $\mathbf{2}$ & 32.740 & 20.143 & 1.732 & 7.872 & 6.409 & 5.652 & 20.810 \\
\hline $\mathbf{3}$ & 32.944 & 22.380 & 1.446 & 8.229 & 6.678 & 5.549 & 21.175 \\
\hline $\mathbf{4}$ & 32.742 & 21.540 & 1.505 & 7.661 & 6.338 & 5.725 & 21.267 \\
\hline $\mathbf{5}$ & 32.781 & 20.809 & 1.353 & 7.774 & 6.403 & 5.232 & 21.450 \\
\hline
\end{tabular}

'HP-7: Heptagon $\left(D_{7 \mathrm{~h}}\right)$; HPY-7: Hexagonal pyramid $\left(C_{6 \mathrm{v}}\right)$; PBPY-7: Pentagonal bipyramid $\left(D_{5 \mathrm{~h}}\right)$; COC-7: Capped octahedron $\left(C_{3 \mathrm{v}}\right)$; CTPR-7: Capped trigonal prism $\left(C_{2 \mathrm{v}}\right)$; JPBPY-7: Johnson pentagonal bipyramid J13 $\left(D_{5 \mathrm{~h}}\right)$; JETPY-7: Johnson elongated triangular pyramid J7 $\left(C_{3 \mathrm{v}}\right)$ 
Table S4. Crystallographic details of 1, 2, 4 and 5.

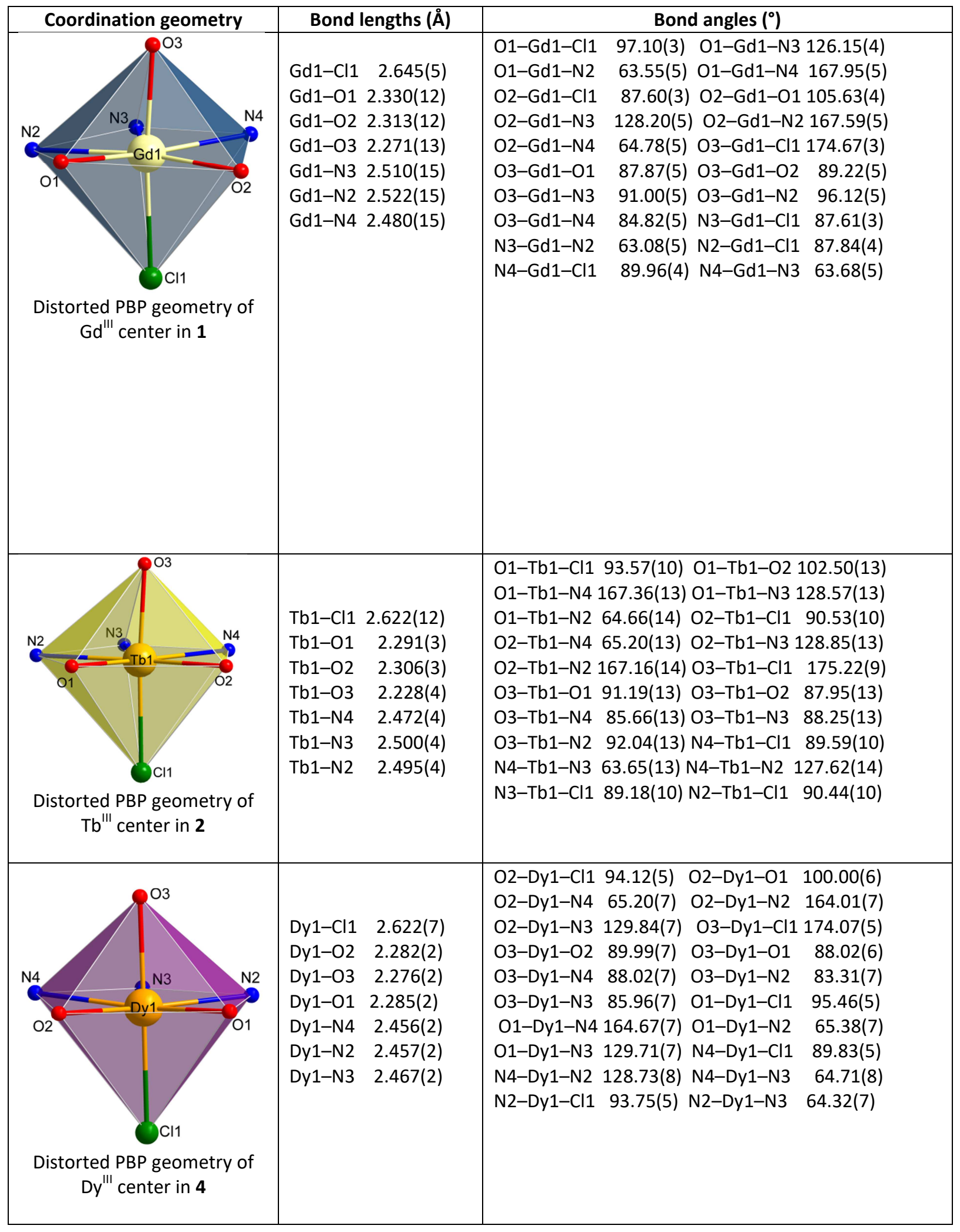




\begin{tabular}{|c|c|c|}
\hline $\begin{array}{l}\text { Distorted PBP geometry of } \\
\text { Er 'II center in } 5\end{array}$ & $\begin{array}{lr}\text { Er1-Cl1 } & 2.591(11) \\
\text { Er1-O1 } & 2.259(3) \\
\text { Er1-O3 } & 2.195(3) \\
\text { Er1-O2 } & 2.268(3) \\
\text { Er1-N3 } & 2.444(4) \\
\text { Er1-N4 } & 2.420(4) \\
\text { Er1-N2 } & 2.432(4)\end{array}$ & $\begin{array}{llll}\text { O1-Er1-Cl1 } & 94.97(9) & \text { O1-Er1-O2 } & 97.78(11) \\
\text { O1-Er1-N3 } & 130.69(11) & \text { O1-Er1-N4 } & 63.78(11) \\
\text { O1-Er1-N2 } & 65.83(12) & \text { O3-Er1-Cl1 } & 174.16(8) \\
\text { O3-Er1-O1 } & 90.83(11) & \text { O3-Er1-O2 } & 89.86(11) \\
\text { O3-Er1-N3 } & 86.83(12) & \text { O3-Er1-N4 } & 85.42(12) \\
\text { O3-Er1-N2 } & 91.81(12) & \text { O2-Er1-Cl1 } & 89.99(8) \\
\text { O2-Er1-N3 } & 131.42(11) & \text { O2-Er1-N4 } & 66.48(11) \\
\text { O2-Er1-N2 } & 163.55(12) & \text { N3-Er1-Cl1 } & 88.89(9) \\
\text { N4-Er1-Cl1 } & 89.16(9) & \text { N4-Er1-N3 } & 64.95(12) \\
\text { N4-Er1-N2 } & 129.97(12) & \text { N2-Er1-Cl1 } & 89.99(9)\end{array}$ \\
\hline
\end{tabular}

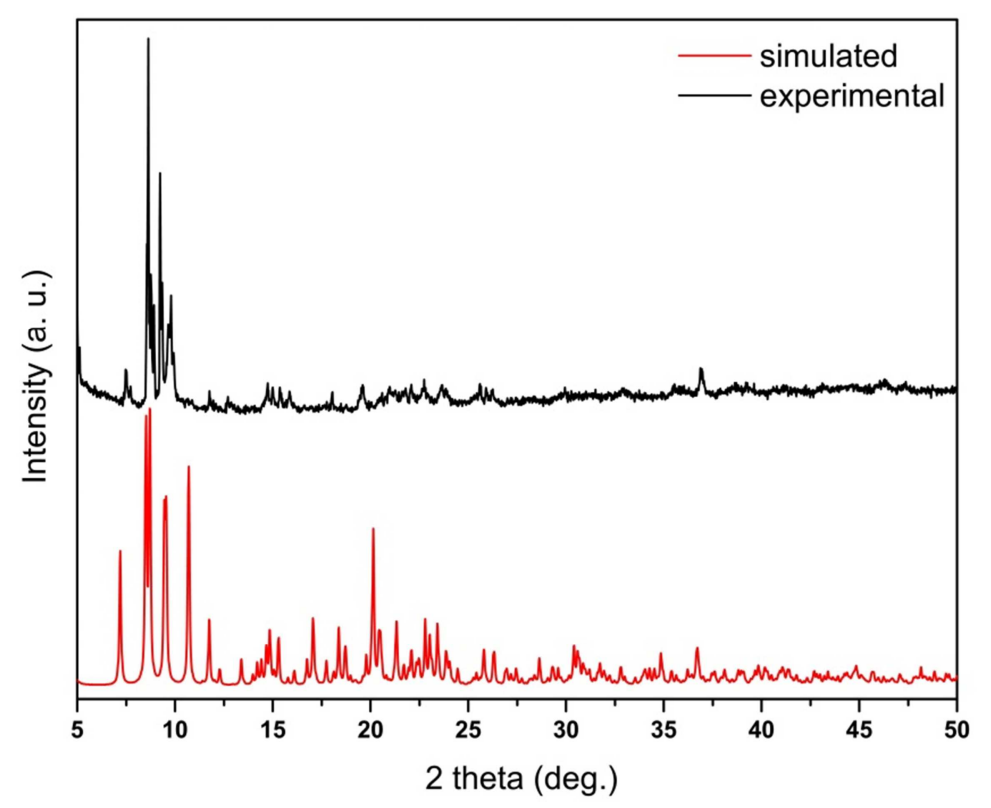

Figure S7. The experimental and simulated powder XRD pattern of complex 3'. 


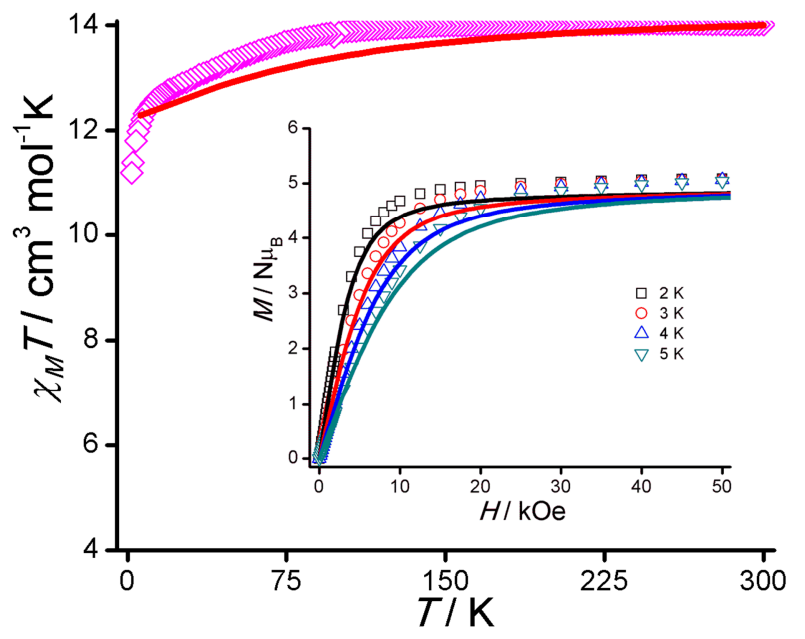

Figure S8. Magnetic behavior for 4. (a) Temperature dependence of $\chi_{\mathrm{M}} T$ and (b) field dependence of the magnetization (inset), solid lines represent the ab initio computed data using MOLCAS 8.2 program.
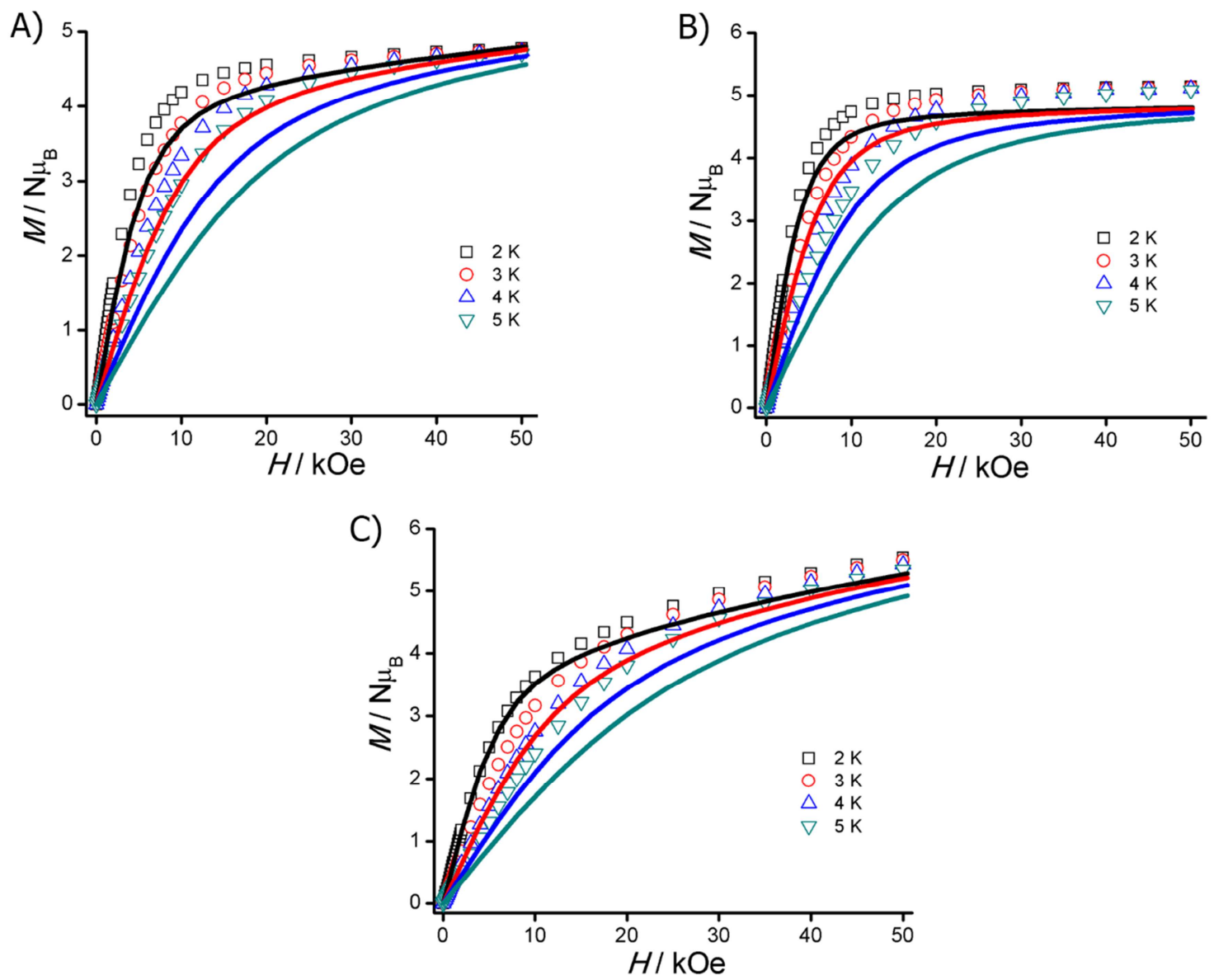

Figure S9. Field dependence of the magnetization (A-C) for complexes $\mathbf{2 - 3}$ and $\mathbf{5}$ respectively, solid lines are the ab initio computed data using MOLCAS 8.2 program. 
Figure S140. temperature dependence of the AC susceptibility in zero field and in an applied field of $1 \mathrm{kOe}$ or 750 Oe for 2 (a), 3 (b), 3' (c), 4 (c), and 5 (e).

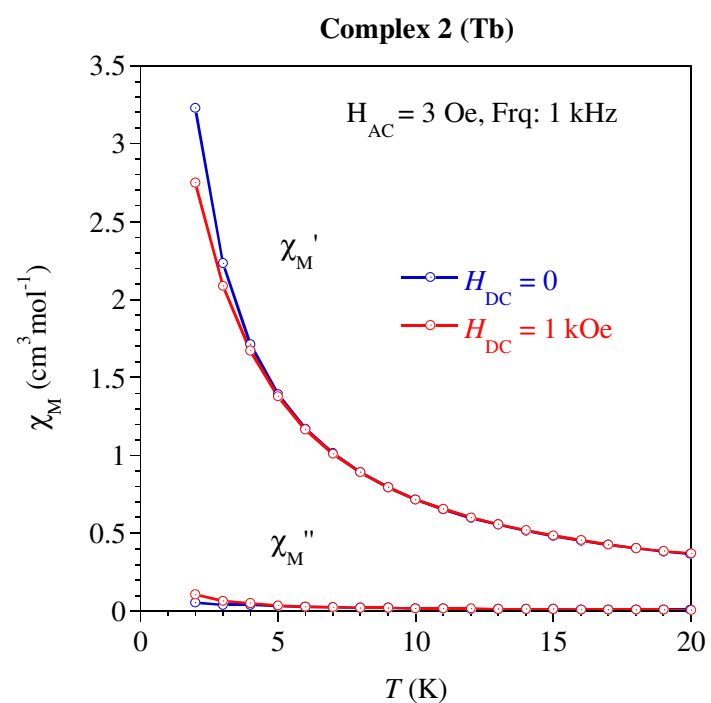

(a)

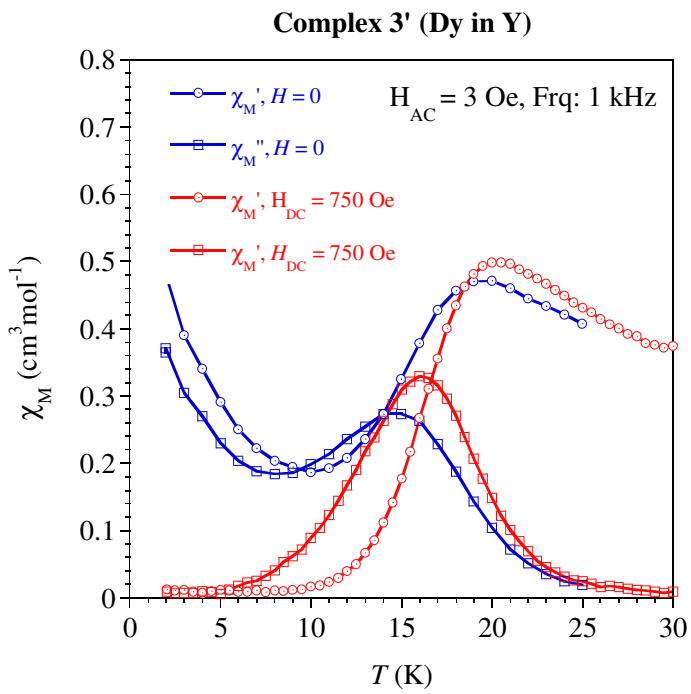

(c)

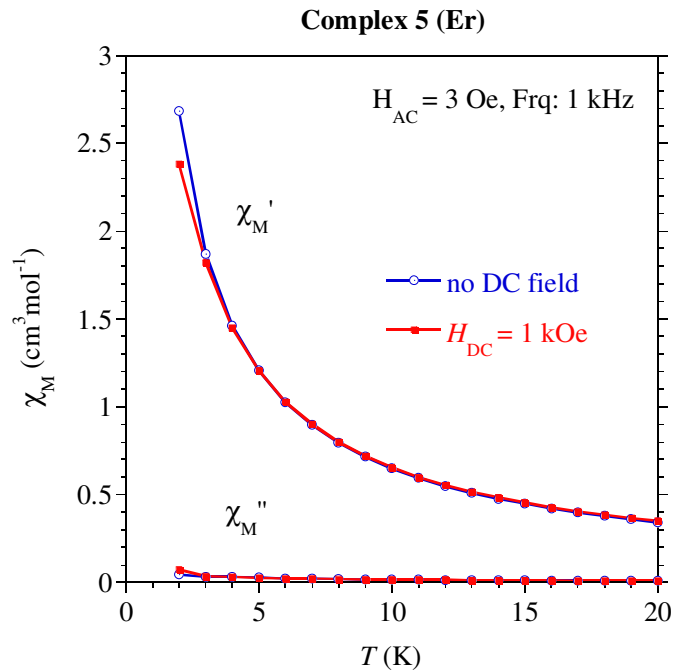

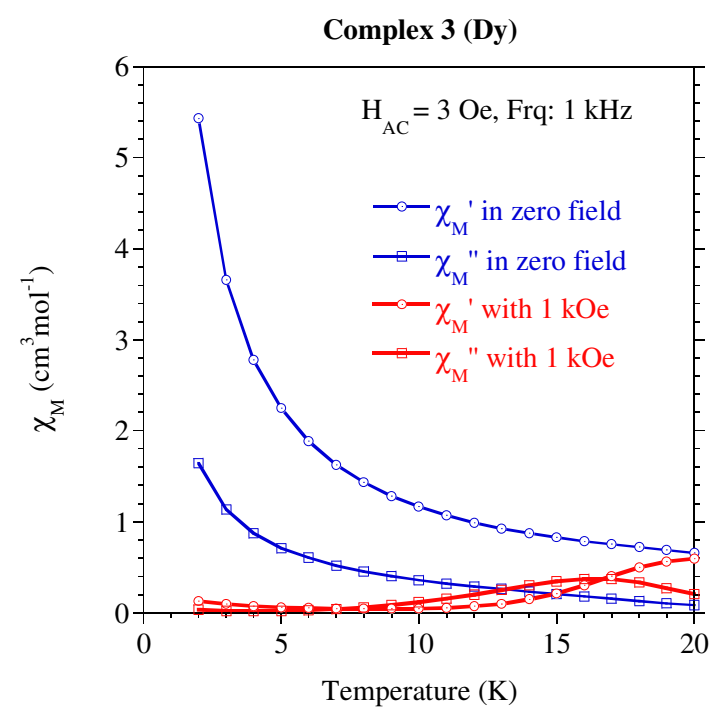

(b)

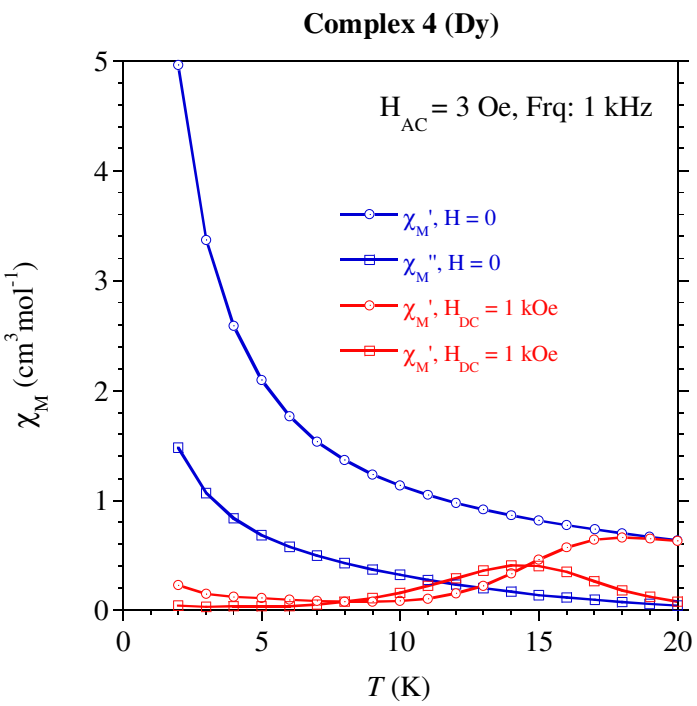

(d)

(e) 

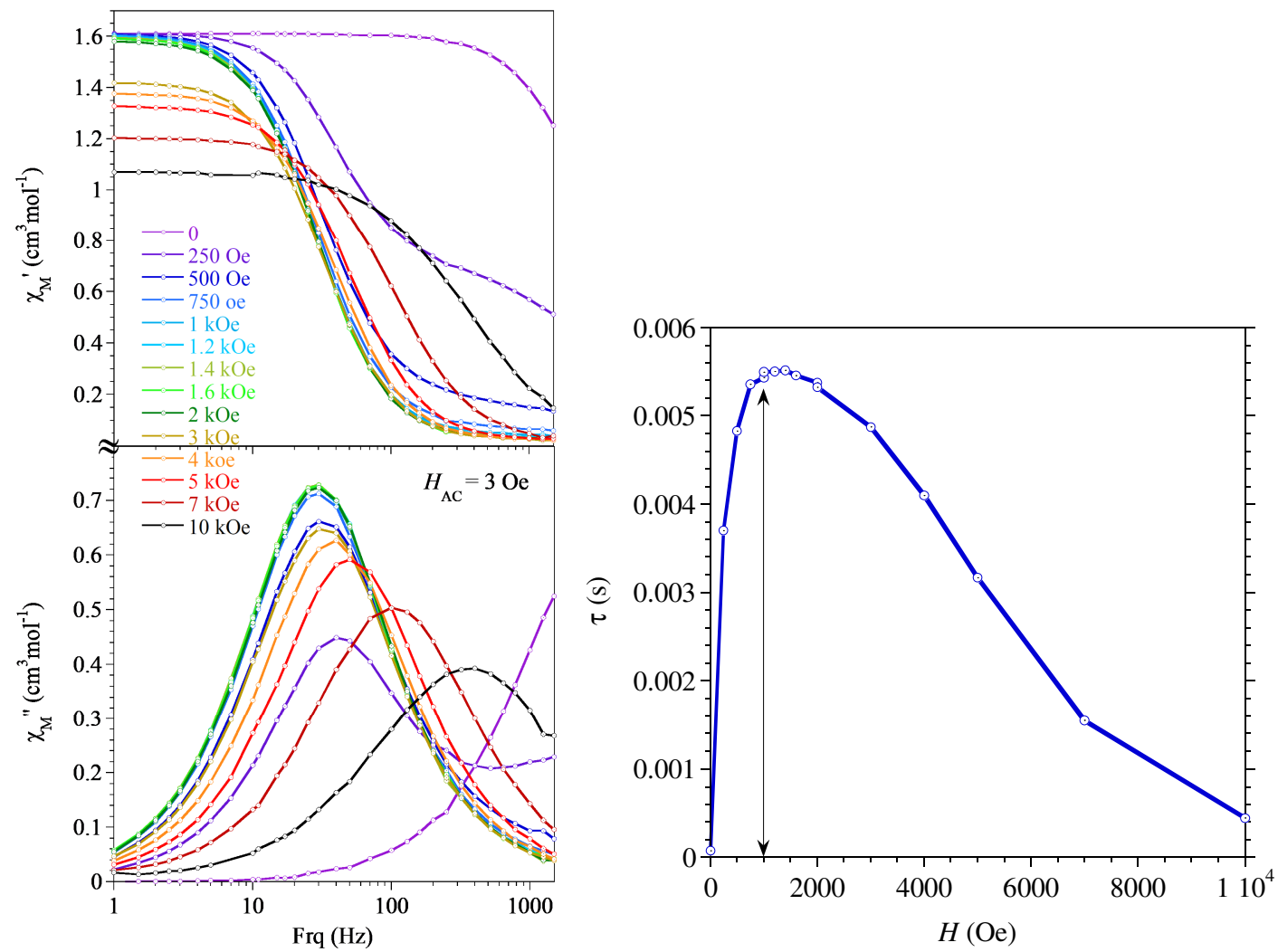

Figure S10. Field dependence of the AC susceptibility (left), and of the relaxation time, $\tau$ (right), for 3 at $8 \mathrm{~K}$. The larger $\tau$ is reached for $1 \mathrm{kOe}$ which was used as applied DC field in the AC studies for this complex. 
Table S5. Best fit parameters of the Debye model to the $\chi^{\prime \prime}{ }_{\mathrm{M}}=f(\mathrm{frq})$ behaviors for 3. $\chi_{\mathrm{T}}$ stands for the isothermal susceptibility, $\chi_{\mathrm{S}}$ for the adiabatic susceptibility, $\tau$ for the relaxation time, and $\alpha$ accounts for the distribution width of the relaxation time.

\begin{tabular}{|c|c|c|c|c|}
\hline $\mathrm{T}(\mathrm{K})$ & $\chi_{T}$ & $\chi_{s}$ & $\tau(s)$ & $\alpha$ \\
\hline 4.5 & 5.71 & 3.29 & 0.11675 & 0.12 \\
\hline 5.0 & 5.61 & 3.39 & 0.065181 & 0.12 \\
\hline 5.5 & 5.52 & 3.47 & 0.038369 & 0.11 \\
\hline 6.0 & 5.45 & 3.55 & 0.024021 & 0.10 \\
\hline 6.5 & 5.38 & 3.61 & 0.015912 & 0.095 \\
\hline 7.0 & 5.33 & 3.67 & 0.011003 & 0.088 \\
\hline 7.5 & 5.28 & 3.72 & 0.007867 & 0.082 \\
\hline 8.0 & 5.24 & 3.76 & 0.005804 & 0.078 \\
\hline 8.5 & 5.20 & 3.80 & 0.004379 & 0.075 \\
\hline 9.0 & 5.16 & 3.84 & 0.003369 & 0.073 \\
\hline 9.5 & 5.13 & 3.87 & 0.002638 & 0.070 \\
\hline 10.0 & 5.10 & 3.90 & 0.002096 & 0.068 \\
\hline 10.5 & 5.07 & 3.93 & 0.001685 & 0.065 \\
\hline 11.0 & 5.05 & 3.95 & 0.001365 & 0.065 \\
\hline 11.5 & 5.02 & 3.97 & 0.001128 & 0.064 \\
\hline 12.0 & 5.00 & 4.00 & 0.000905 & 0.063 \\
\hline 12.5 & 4.98 & 4.01 & 0.00075741 & 0.060 \\
\hline 13.0 & 4.97 & 4.03 & 0.0006327 & 0.059 \\
\hline 13.5 & 4.95 & 4.05 & 0.00053185 & 0.057 \\
\hline 14.0 & 4.94 & 4.06 & 0.00044954 & 0.056 \\
\hline 14.5 & 4.92 & 4.08 & 0.00037815 & 0.056 \\
\hline 15.0 & 4.91 & 4.09 & 0.00031952 & 0.055 \\
\hline 15.5 & 3.90 & 3.10 & 0.00027045 & 0.055 \\
\hline 16.0 & 3.88 & 3.11 & 0.00022847 & 0.052 \\
\hline 16.5 & 3.87 & 3.13 & 0.00019351 & 0.050 \\
\hline 17.0 & 3.86 & 3.14 & 0.0001633 & 0.048 \\
\hline 17.5 & 4.35 & 3.65 & 0.00013939 & 0.042 \\
\hline 18.0 & 3.84 & 3.16 & 0.00011626 & 0.041 \\
\hline
\end{tabular}




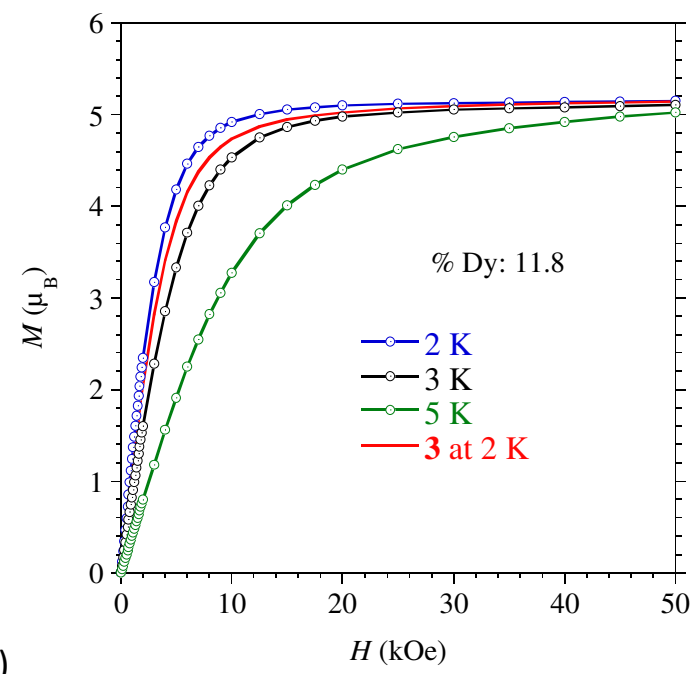

(a)
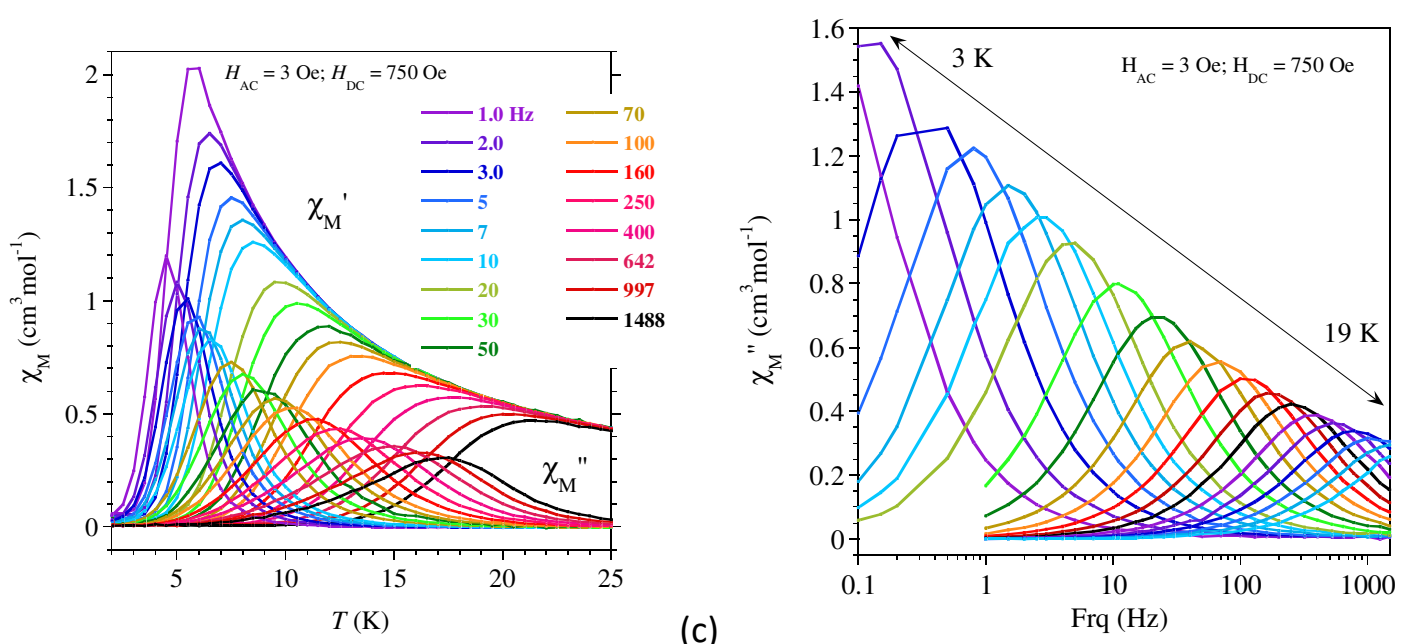

(b)

(c)

Figure S12. Magnetic behavior for 3'. The composition in Dy ${ }^{\mathrm{III}}$ for the sample was estimated by adjusting the magnetization reached for $3^{\prime}$ under $5 \mathrm{t}$ at $2 \mathrm{~K}$ (blue plot in (a)) to that of $\mathbf{3}$ at same temperature (red plot). 
Table S4. Best fit parameters of the Debye model to the $\chi_{M}^{\prime \prime}=f($ frq $)$ behaviors for $3^{\prime} . \chi_{\mathrm{T}}$ stands for the isothermal susceptibility, $\chi_{\mathrm{S}}$ for the adiabatic susceptibility, $\tau$ for the relaxation time, and $\alpha$ accounts for the distribution width of the relaxation time.

\begin{tabular}{|c|c|c|c|c|}
\hline $\mathrm{T}(\mathrm{K})$ & $\chi_{T}$ & $x_{s}$ & $\tau(\mathrm{s})$ & $\alpha$ \\
\hline 4.0 & 5.825 & 3.175 & 0.166 & 0.16 \\
\hline 4.5 & 5.6816 & 3.3184 & 0.080 & 0.11 \\
\hline 5.0 & 5.5944 & 3.4056 & 0.04511 & 0.062 \\
\hline 5.5 & 5.5049 & 3.4951 & 0.02776 & 0.064 \\
\hline 6.0 & 5.4324 & 3.5677 & 0.0178 & 0.0558 \\
\hline 6.5 & 5.3645 & 3.6355 & 0.01177 & 0.0573 \\
\hline 7.0 & 5.3137 & 3.6863 & 0.00817 & 0.052 \\
\hline 7.5 & 5.2669 & 3.7331 & 0.00577 & 0.048 \\
\hline 8.0 & 5.2233 & 3.7767 & 0.00417 & 0.044 \\
\hline 8.5 & 5.1878 & 3.8122 & 0.00306 & 0.034 \\
\hline 9.0 & 5.1514 & 3.8486 & 0.00230 & 0.035 \\
\hline 9.5 & 5.119 & 3.881 & 0.001747 & 0.037 \\
\hline 10.0 & 5.0922 & 3.9078 & 0.001341 & 0.027 \\
\hline 10.5 & 5.0658 & 3.9342 & 0.001049 & 0.032 \\
\hline 11.0 & 5.0435 & 3.9565 & 0.000825 & 0.026 \\
\hline 11.5 & 5.0224 & 3.9776 & 0.000656 & 0.023 \\
\hline 12.0 & 5.001 & 3.999 & 0.000517 & 0.018 \\
\hline 12.5 & 4.9822 & 4.0178 & 0.000421 & 0.023 \\
\hline 13.0 & 4.9661 & 4.0339 & 0.0003419 & 0.020 \\
\hline 13.5 & 4.9513 & 4.0487 & 0.0002823 & 0.011 \\
\hline 14.0 & 4.9367 & 4.0633 & 0.000233 & 0.008 \\
\hline 14.5 & 4.9235 & 4.0765 & 0.0001895 & 0.013 \\
\hline 15.0 & 4.9127 & 4.0873 & 0.000156 & 0.01 \\
\hline 15.5 & 4.9004 & 4.0996 & 0.000128 & $6 e-5$ \\
\hline 16.0 & 4.89 & 4.11 & 0.0001045 & 0.002 \\
\hline 16.5 & 4.8769 & 4.1231 & $8.57 e-5$ & 0.0005 \\
\hline
\end{tabular}



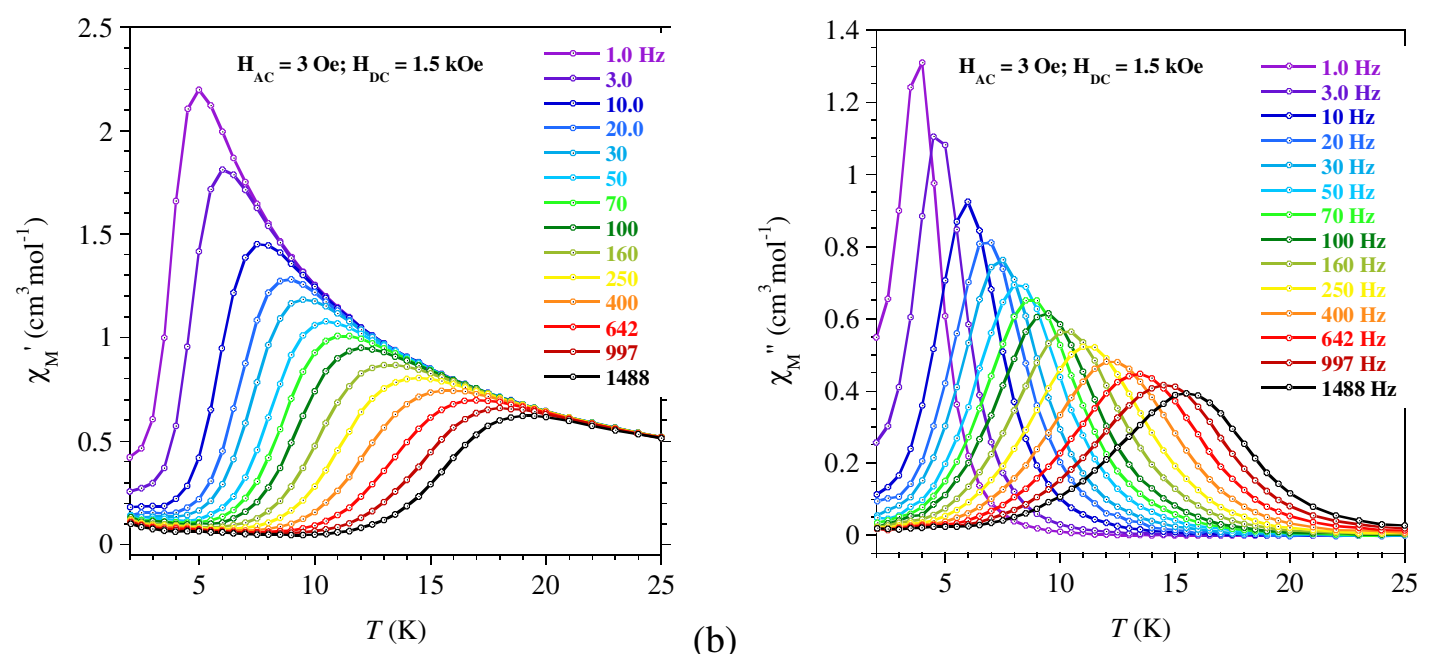

(a)

(b)

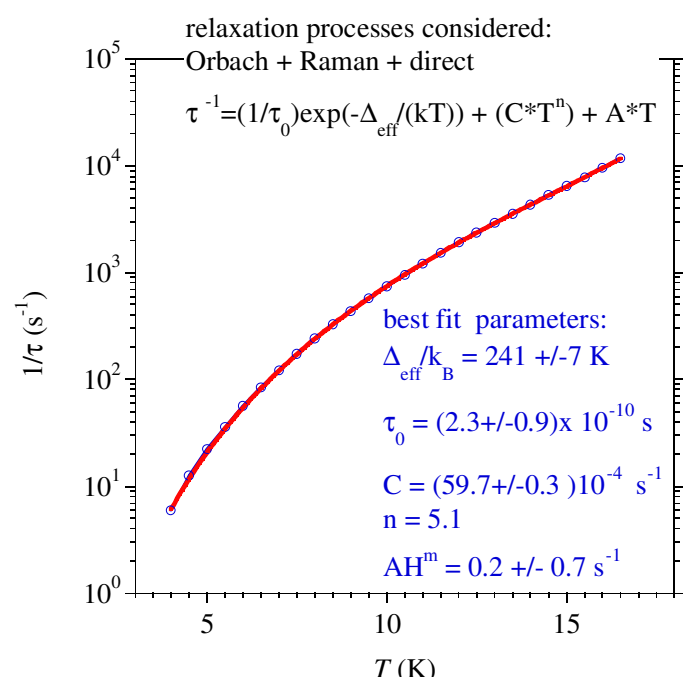

(c)

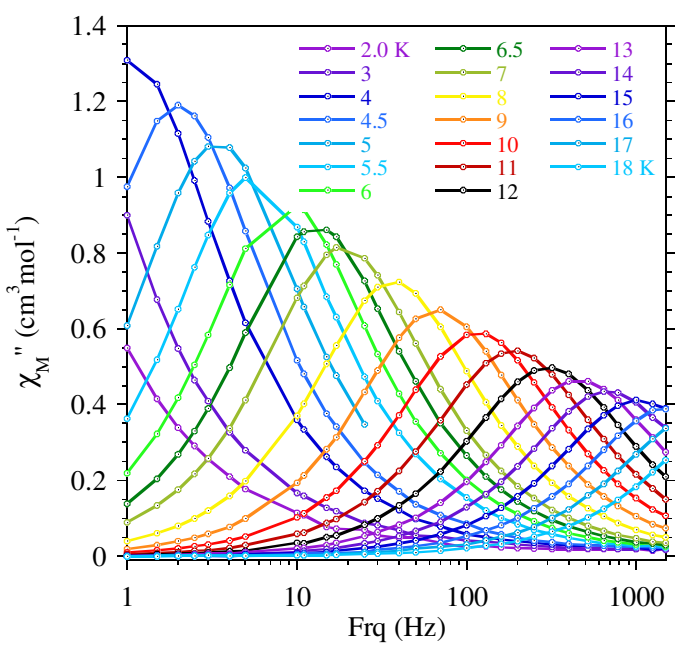

(d)

$T(\mathrm{~K})$

Figure S12. AC susceptibiliy behavior for 4 . 
Table S7. Best fit parameters of the Debye model to the $\chi^{\prime \prime}{ }_{\mathrm{M}}=f(\mathrm{frq})$ behaviors for $4 . \chi_{\mathrm{T}}$ stands for the isothermal susceptibility, $\chi_{\mathrm{S}}$ for the adiabatic susceptibility, $\tau$ for the relaxation time, and $\alpha$ accounts for the distribution width of the relaxation time.

\begin{tabular}{|c|c|c|c|c|}
\hline $\mathrm{T}(\mathrm{K})$ & $\chi_{T}$ & $\chi_{s}$ & $\tau(\mathrm{s})$ & $\alpha$ \\
\hline 4.0 & 5.825 & 3.175 & 0.166 & 0.16 \\
\hline 4.5 & 5.6816 & 3.3184 & 0.080 & 0.11 \\
\hline 5.0 & 5.5944 & 3.4056 & 0.04511 & 0.062 \\
\hline 5.5 & 5.5049 & 3.4951 & 0.02776 & 0.064 \\
\hline 6.0 & 5.4324 & 3.5677 & 0.0178 & 0.0558 \\
\hline 6.5 & 5.3645 & 3.6355 & 0.01177 & 0.0573 \\
\hline 7.0 & 5.3137 & 3.6863 & 0.00817 & 0.052 \\
\hline 7.5 & 5.2669 & 3.7331 & 0.00577 & 0.048 \\
\hline 8.0 & 5.2233 & 3.7767 & 0.00417 & 0.044 \\
\hline 8.5 & 5.1878 & 3.8122 & 0.00306 & 0.034 \\
\hline 9.0 & 5.1514 & 3.8486 & 0.00230 & 0.035 \\
\hline 9.5 & 5.119 & 3.881 & 0.001747 & 0.037 \\
\hline 10.0 & 5.0922 & 3.9078 & 0.001341 & 0.027 \\
\hline 10.5 & 5.0658 & 3.9342 & 0.001049 & 0.032 \\
\hline 11.0 & 5.0435 & 3.9565 & 0.000825 & 0.026 \\
\hline 11.5 & 5.0224 & 3.9776 & 0.000656 & 0.023 \\
\hline 12.0 & 5.001 & 3.999 & 0.000517 & 0.018 \\
\hline 12.5 & 4.9822 & 4.0178 & 0.000421 & 0.023 \\
\hline 13.0 & 4.9661 & 4.0339 & 0.0003419 & 0.020 \\
\hline 13.5 & 4.9513 & 4.0487 & 0.0002823 & 0.011 \\
\hline 14.0 & 4.9367 & 4.0633 & 0.000233 & 0.008 \\
\hline 14.5 & 4.9235 & 4.0765 & 0.0001895 & 0.013 \\
\hline 15.0 & 4.9127 & 4.0873 & 0.000156 & 0.01 \\
\hline 15.5 & 4.9004 & 4.0996 & 0.000128 & $6 e-5$ \\
\hline 16.0 & 4.89 & 4.11 & 0.0001045 & 0.002 \\
\hline 16.5 & 4.8769 & 4.1231 & $8.57 e-5$ & 0.0005 \\
\hline
\end{tabular}

Table S8. Basis set used for all the elements in our calculation.

\begin{tabular}{|c|c|}
\hline Elements & Basis set \\
\hline $\mathrm{H}$ & H.ANO-RCC..2s. \\
\hline $\mathrm{C}$ & C.ANO-RCC...3s2p. \\
\hline $\mathrm{N}$ & N.ANO-RCC...4s3p2d1f. \\
\hline $\mathrm{O}$ & O.ANO-RCC...4s3p2d1f. \\
\hline $\mathrm{P}$ & P.ANO-RCC...4s3p. \\
\hline $\mathrm{Cl}$ & Cl.ANO-RCC...5s4p2d1f. \\
\hline $\mathrm{Tb}$ & Tb.ANO-RCC...8s7p5d3f2g1h. \\
\hline Dy & Dy.ANO-RCC...7s6p4d2f1g. \\
\hline
\end{tabular}


(a)

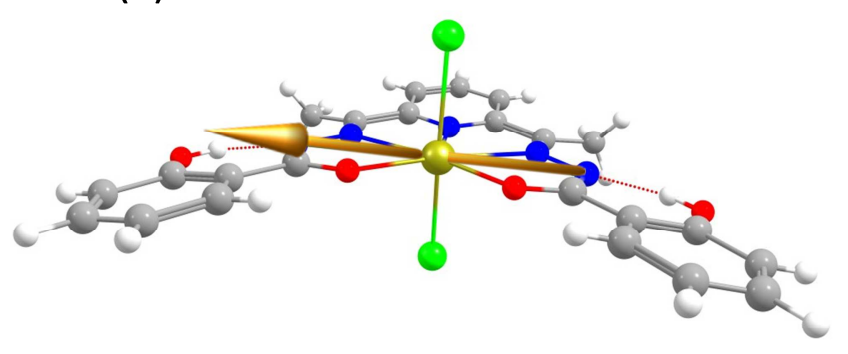

(b)

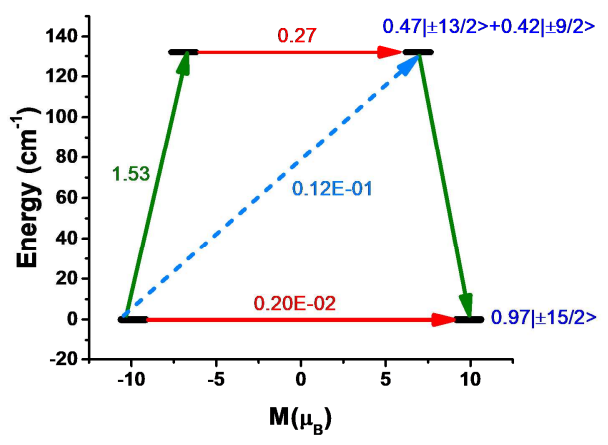

Figure S14. Computed $g_{z z}$ orientation in complex 6 (a) and possible magnetization relaxation pathways (b). The red arrows show the QTM and TA-QTM via ground and higher excited KD respectively. The sky dotted arrows show the Orbach process for the relaxation. The green arrows show the possible mechanism of magnetic relaxation. The blue characters imply the $\mathrm{m}_{\mathrm{J}}$ composition of the KDs.
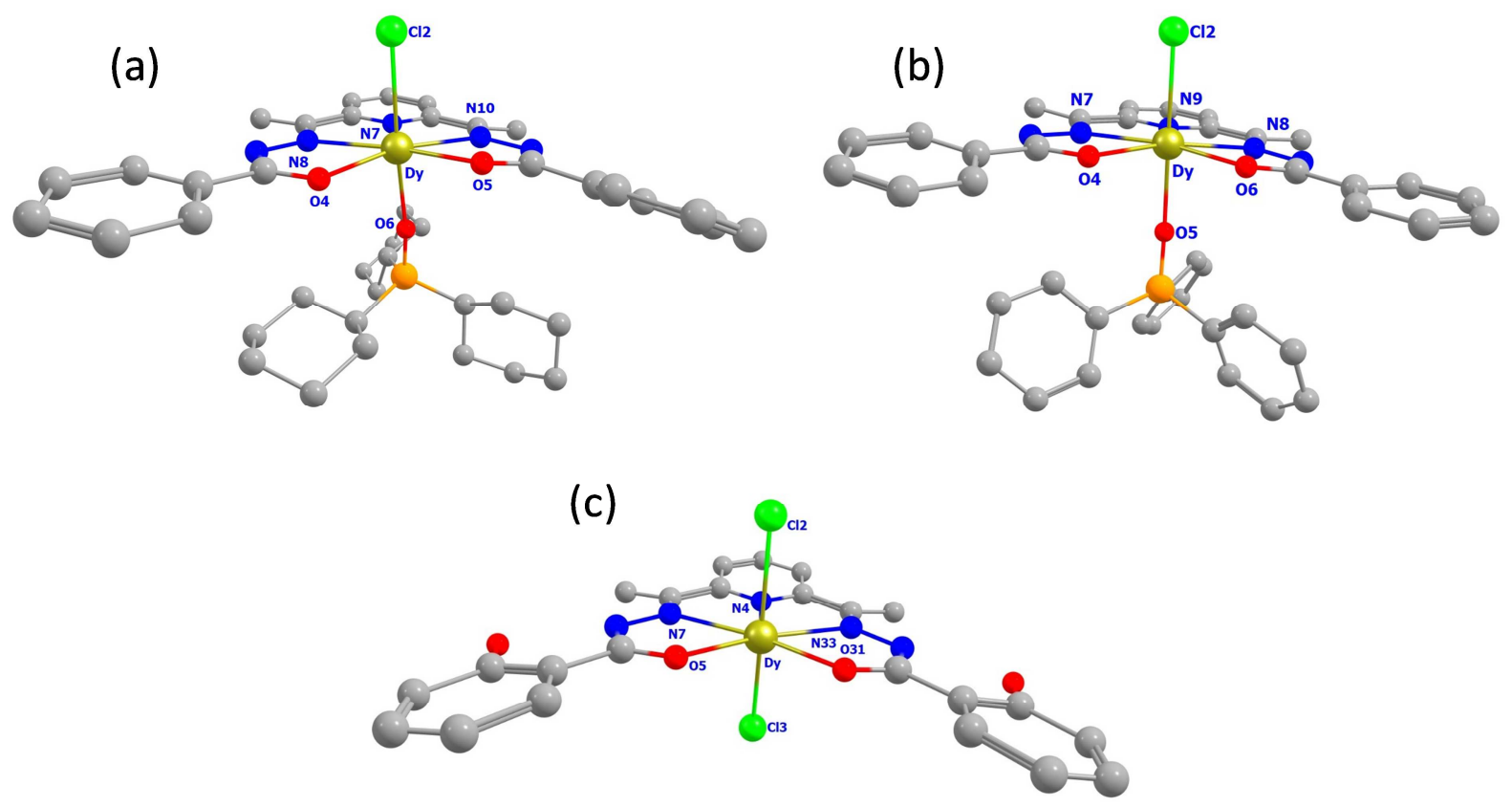

Figure S15. Atom number for Loprop charge of complex (A) 3 (B) 4 (C) 6. Colour code: Dygreenish yellow, Cl-green, P-violet, O-red, N-blue, C-grey. Hydrogens are removed for clarity. 
Table S9. LoProp charge of the metal center and its coordinated atom of complex 3,4 and $\mathbf{6}$.

\begin{tabular}{|c|c|c|c|}
\hline Atom & $\mathbf{3}$ & $\mathbf{4}$ & $\mathbf{6}$ \\
\hline Dy & 2.5006 & 2.4993 & 2.4656 \\
\hline O6/O5/Cl1 & -1.1346 & -1.1107 & -0.8799 \\
\hline $\mathrm{Cl} 2$ & -0.8781 & -0.8753 & -0.8713 \\
\hline O4/O4/O5 & -0.8314 & -0.8228 & -0.8236 \\
\hline O5/O6/O31 & -0.8242 & -0.8283 & -0.8239 \\
\hline $\mathrm{N} 7 / \mathrm{N} 7 / \mathrm{N} 4$ & -0.3882 & -0.2262 & -0.3726 \\
\hline $\mathrm{N} 8 / \mathrm{N} 8 / \mathrm{N} 7$ & -0.2568 & -0.2542 & -0.2660 \\
\hline $\mathrm{N} 10 / \mathrm{N} 9 / \mathrm{N} 33$ & -0.2497 & -0.3908 & -0.2662 \\
\hline Av. axial/av. Equatorial & 1.9730 & 1.9684 & 1.7153 \\
\hline
\end{tabular}

Table S10. The ab initio computed crystal field parameter of complex 3, 4 and 6.

\begin{tabular}{|c|c|c|c|c|}
\hline \multirow{2}{*}{ k } & \multirow{2}{*}{$Q$} & \multicolumn{3}{|c|}{$B_{k}^{q}$} \\
\hline & & 3 & 4 & 6 \\
\hline \multirow{5}{*}{2} & -2 & $1.20 \mathrm{E}-01$ & $-1.63 \mathrm{E}-02$ & $-1.52 \mathrm{E}-02$ \\
\hline & -1 & $-5.59 \mathrm{E}-02$ & $-2.09 \mathrm{E}-02$ & $1.34 \mathrm{E}-02$ \\
\hline & 0 & $-2.18 E+00$ & $-2.32 E+00$ & $-2.80 E+00$ \\
\hline & 1 & $-1.13 \mathrm{E}-01$ & $-7.01 \mathrm{E}-01$ & $4.89 \mathrm{E}-03$ \\
\hline & 2 & $-2.14 \mathrm{E}-01$ & $2.34 \mathrm{E}-01$ & $1.77 \mathrm{E}+00$ \\
\hline \multirow{9}{*}{4} & -4 & $1.70 \mathrm{E}-02$ & $-2.97 \mathrm{E}-03$ & $1.26 \mathrm{E}-03$ \\
\hline & -3 & $3.73 \mathrm{E}-04$ & $-5.85 \mathrm{E}-04$ & $4.58 \mathrm{E}-04$ \\
\hline & -2 & $-1.22 \mathrm{E}-02$ & $2.32 \mathrm{E}-03$ & $-8.19 \mathrm{E}-05$ \\
\hline & -1 & $-3.69 \mathrm{E}-04$ & $-1.81 \mathrm{E}-04$ & $1.91 \mathrm{E}-04$ \\
\hline & 0 & $-1.57 \mathrm{E}-03$ & $-1.41 \mathrm{E}-03$ & $-8.93 E-04$ \\
\hline & 1 & $-7.93 \mathrm{E}-04$ & $2.33 \mathrm{E}-03$ & $-2.42 \mathrm{E}-07$ \\
\hline & 2 & $4.28 \mathrm{E}-02$ & $4.22 \mathrm{E}-02$ & 4.04E-02 \\
\hline & 3 & $6.25 \mathrm{E}-03$ & $-2.79 \mathrm{E}-03$ & $-7.15 \mathrm{E}-05$ \\
\hline & 4 & $-3.02 \mathrm{E}-02$ & $-3.35 \mathrm{E}-02$ & $-2.75 \mathrm{E}-02$ \\
\hline \multirow{13}{*}{6} & -6 & $-4.13 E-05$ & $2.50 \mathrm{E}-05$ & $1.59 \mathrm{E}-05$ \\
\hline & -5 & $-8.33 \mathrm{E}-06$ & $1.29 E-05$ & $-1.89 \mathrm{E}-06$ \\
\hline & -4 & $-2.58 \mathrm{E}-05$ & $2.40 \mathrm{E}-05$ & 8.27E-06 \\
\hline & -3 & $4.59 \mathrm{E}-05$ & 1.16E-05 & $-4.35 E-06$ \\
\hline & -2 & 7.59E-05 & 2.63E-05 & $2.53 \mathrm{E}-05$ \\
\hline & -1 & $3.82 \mathrm{E}-05$ & $1.42 \mathrm{E}-05$ & $-7.95 \mathrm{E}-06$ \\
\hline & 0 & $-5.50 \mathrm{E}-05$ & $-5.30 \mathrm{E}-05$ & $-4.64 \mathrm{E}-05$ \\
\hline & 1 & $9.50 \mathrm{E}-06$ & $2.02 \mathrm{E}-05$ & $-4.09 \mathrm{E}-07$ \\
\hline & 2 & $-4.03 E-04$ & $-4.02 \mathrm{E}-04$ & $-4.20 \mathrm{E}-04$ \\
\hline & 3 & $-7.82 \mathrm{E}-05$ & $-3.79 \mathrm{E}-05$ & $3.72 \mathrm{E}-07$ \\
\hline & 4 & $6.56 \mathrm{E}-06$ & $7.68 \mathrm{E}-06$ & $5.92 \mathrm{E}-05$ \\
\hline & 5 & 3.19E-05 & $6.33 \mathrm{E}-05$ & $-3.51 \mathrm{E}-07$ \\
\hline & 6 & $-1.06 \mathrm{E}-05$ & $3.32 \mathrm{E}-05$ & $-4.81 \mathrm{E}-05$ \\
\hline
\end{tabular}


Table S11. The $a b$ initio computed energy and the associated g-tensors of the low lying KDs generated from ${ }^{6} \mathrm{H}_{15 / 2}$ state of complexes $3 \mathbf{a}, 4 \mathbf{a}$ and $\mathbf{6 a}$.

\begin{tabular}{|c|c|c|c|c|}
\hline Energy (K) & $g_{x}$ & $g_{y}$ & $g_{z}$ & $\begin{array}{c}\text { Angle of } \mathrm{g}_{\mathrm{zz}} \text { between } \\
\text { ground and higher excited } \\
\text { states }\left({ }^{\circ}\right)\end{array}$ \\
\hline \multicolumn{4}{|c|}{ Complex 3a } & \\
\hline 0.0 & 0.000 & 0.000 & 20.019 & \\
\hline 800.9 & 0.000 & 0.000 & 17.033 & 0.10 \\
\hline 1541.7 & 0.002 & 0.002 & 14.169 & 0.21 \\
\hline 2141.7 & 0.020 & 0.022 & 11.502 & 0.94 \\
\hline 2540.6 & 0.531 & 0.554 & 8.987 & 3.32 \\
\hline 2748.4 & 0.145 & 0.914 & 6.536 & 10.87 \\
\hline 2829.7 & 7.252 & 6.383 & 3.190 & 6.36 \\
\hline 2864.3 & 0.768 & 3.319 & 16.642 & 89.83 \\
\hline \multicolumn{4}{|c|}{ Complex 4a } & \\
\hline 0.0 & 0.000 & 0.000 & 20.011 & \\
\hline 777.5 & 0.000 & 0.000 & 17.036 & 0.05 \\
\hline 1498.5 & 0.002 & 0.002 & 14.178 & 0.12 \\
\hline 2082.8 & 0.017 & 0.020 & 11.210 & 0.30 \\
\hline 2471.6 & 0.535 & 0.555 & 8.984 & 0.83 \\
\hline 2674.8 & 0.263 & 0.810 & 6.456 & 2.52 \\
\hline 2754.0 & 7.353 & 6.364 & 3.297 & 1.32 \\
\hline 2787.4 & 0.722 & 3.008 & 16.723 & 89.94 \\
\hline \multicolumn{4}{|c|}{ Complex 6a } & \\
\hline 0.0 & 0.000 & 0.000 & 20.011 & \\
\hline 712.9 & 0.000 & 0.000 & 17.066 & 0.14 \\
\hline 1362.0 & 0.009 & 0.010 & 14.234 & 0.22 \\
\hline 1886.7 & 0.065 & 0.083 & 11.553 & 0.29 \\
\hline 2248.4 & 1.525 & 1.581 & 8.899 & 0.51 \\
\hline 2459.8 & 0.761 & 2.190 & 6.268 & 1.54 \\
\hline 2555.0 & 7.933 & 7.690 & 3.001 & 0.80 \\
\hline 2616.8 & 0.510 & 1.867 & 17.633 & 90.00 \\
\hline
\end{tabular}

Table S12. LoProp charge of the metal center and its coordinated atom of complex $\mathbf{3 a}, \mathbf{4 a}$ and $\mathbf{6 a}$.

\begin{tabular}{|c|c|c|c|}
\hline Atom & 3a & 4a & 6a \\
\hline Dy & 2.6301 & 2.6357 & 2.5568 \\
\hline $\mathrm{O} / \mathrm{O} 5 / \mathrm{Cl} 1$ & -1.2234 & -1.2172 & -0.7804 \\
\hline $\mathrm{Cl} 2$ & -0.7576 & -0.7519 & -0.7764 \\
\hline
\end{tabular}


Table S13. The $a b$ initio computed crystal field parameter of complex 3a, 4a and $6 \mathbf{a}$.

\begin{tabular}{|c|c|c|c|c|}
\hline \multirow{2}{*}{$\mathrm{k}$} & \multirow{2}{*}{$Q$} & \multicolumn{3}{|c|}{$B_{k}^{q}$} \\
\hline & & $3 a$ & $4 a$ & $6 a$ \\
\hline \multirow{5}{*}{2} & -2 & $9.10 \mathrm{E}-02$ & $2.95 \mathrm{E}-02$ & $3.18 \mathrm{E}-07$ \\
\hline & -1 & $-9.54 \mathrm{E}-02$ & $6.71 \mathrm{E}-02$ & $-2.31 \mathrm{E}-08$ \\
\hline & 0 & $-1.21 E+01$ & $-1.18 E+01$ & $-1.10 \mathrm{E}+01$ \\
\hline & 1 & $5.94 \mathrm{E}-02$ & $-1.57 \mathrm{E}-02$ & $9.50 \mathrm{E}-02$ \\
\hline & 2 & $2.24 \mathrm{E}-01$ & $1.81 \mathrm{E}-01$ & $-4.22 \mathrm{E}-01$ \\
\hline \multirow{9}{*}{4} & -4 & $-2.18 \mathrm{E}-04$ & $-8.87 \mathrm{E}-06$ & $-3.74 \mathrm{E}-09$ \\
\hline & -3 & $-1.11 \mathrm{E}-03$ & $6.57 \mathrm{E}-04$ & $5.79 \mathrm{E}-10$ \\
\hline & -2 & $1.22 \mathrm{E}-04$ & $-1.63 E-05$ & $-8.69 \mathrm{E}-10$ \\
\hline & -1 & $1.82 \mathrm{E}-03$ & $-5.31 \mathrm{E}-04$ & $1.48 \mathrm{E}-10$ \\
\hline & 0 & $-6.49 \mathrm{E}-03$ & $-6.26 \mathrm{E}-03$ & $-4.60 \mathrm{E}-03$ \\
\hline & 1 & $-3.44 \mathrm{E}-04$ & 4.15E-05 & $-4.11 \mathrm{E}-04$ \\
\hline & 2 & $-4.40 \mathrm{E}-04$ & $-7.07 \mathrm{E}-04$ & $1.10 \mathrm{E}-03$ \\
\hline & 3 & $1.62 \mathrm{E}-04$ & $2.90 \mathrm{E}-04$ & $-5.07 \mathrm{E}-04$ \\
\hline & 4 & $-1.44 \mathrm{E}-03$ & $-1.42 \mathrm{E}-03$ & $2.49 \mathrm{E}-03$ \\
\hline \multirow{13}{*}{6} & -6 & $7.25 \mathrm{E}-06$ & $4.93 \mathrm{E}-07$ & $2.17 \mathrm{E}-10$ \\
\hline & -5 & $-1.04 \mathrm{E}-05$ & 4.44E-06 & $-2.51 \mathrm{E}-10$ \\
\hline & -4 & $-3.17 E-06$ & $-1.78 \mathrm{E}-07$ & $-6.33 E-11$ \\
\hline & -3 & $-6.28 \mathrm{E}-06$ & 4.31E-06 & $3.35 E-11$ \\
\hline & -2 & $-3.51 \mathrm{E}-06$ & $1.24 \mathrm{E}-07$ & $3.57 \mathrm{E}-12$ \\
\hline & -1 & $-1.95 \mathrm{E}-05$ & $1.86 \mathrm{E}-06$ & $4.14 \mathrm{E}-13$ \\
\hline & 0 & 4.16E-05 & $4.05 \mathrm{E}-05$ & $2.85 \mathrm{E}-05$ \\
\hline & 1 & $-2.99 \mathrm{E}-06$ & $1.34 \mathrm{E}-06$ & $-4.29 E-06$ \\
\hline & 2 & $-1.31 E-06$ & $4.71 \mathrm{E}-06$ & $-5.29 E-06$ \\
\hline & 3 & $-3.64 \mathrm{E}-06$ & $-1.01 \mathrm{E}-06$ & $-3.47 \mathrm{E}-05$ \\
\hline & 4 & $-2.27 \mathrm{E}-05$ & $-2.39 E-05$ & 4.47E-05 \\
\hline & 5 & $1.68 \mathrm{E}-05$ & $-2.43 E-06$ & 1.39E-04 \\
\hline & 6 & $3.38 \mathrm{E}-05$ & $3.37 \mathrm{E}-05$ & $-1.02 \mathrm{E}-04$ \\
\hline
\end{tabular}

Table S14. The $a b$ initio computed energy with the associated g-tensors and tunneling splitting $\left(\Delta_{\text {tun }}\right)$ of the low lying energy levels of complexes $\mathbf{2}$.

\begin{tabular}{|c|c|c|c|}
\hline Levels & Energy (K) & $g_{z z}$ & $\Delta_{\text {tun }}$ \\
\hline 1 & 0 & \multirow{2}{*}{16.69} & \multirow{2}{*}{1.88} \\
\hline 2 & 2.7072 & & \\
\hline 3 & 64.8432 & \multirow{2}{*}{13.745} & \multirow{2}{*}{4.82} \\
\hline 4 & 71.784 & & \\
\hline 5 & 261.72 & \multirow{2}{*}{10.003} & \multirow{2}{*}{8.98} \\
\hline 6 & 274.6512 & & \\
\hline 7 & 550.5984 & \multirow{2}{*}{14.163} & \multirow{2}{*}{13.08} \\
\hline 8 & 569.4336 & & \\
\hline
\end{tabular}


Table S15. The ab initio computed energy $\left(\mathrm{cm}^{-1}\right)$ with the associated g-tensors of the eight low lying KDs of complexes $\mathbf{5}$.

\begin{tabular}{|c|c|c|c|}
\hline \multicolumn{5}{|c|}{ Complex 5 } \\
\hline Energy $(\mathrm{K})$ & $\mathrm{g}_{\mathrm{x}}$ & $\mathrm{g}_{\mathrm{y}}$ & $\mathrm{g}_{\mathrm{z}}$ \\
\hline 0.0 & 0.089 & 1.396 & 14.176 \\
\hline 20.7 & 1.608 & 3.471 & 12.510 \\
\hline 50.3 & 0.220 & 4.998 & 11.662 \\
\hline 185.5 & 3.176 & 4.926 & 9.333 \\
\hline 320.7 & 0.882 & 2.076 & 12.297 \\
\hline 403.1 & 1.227 & 3.722 & 14.512 \\
\hline 610.4 & 0.026 & 0.672 & 15.353 \\
\hline 632.3 & 0.229 & 0.671 & 15.370 \\
\hline
\end{tabular}

(a)

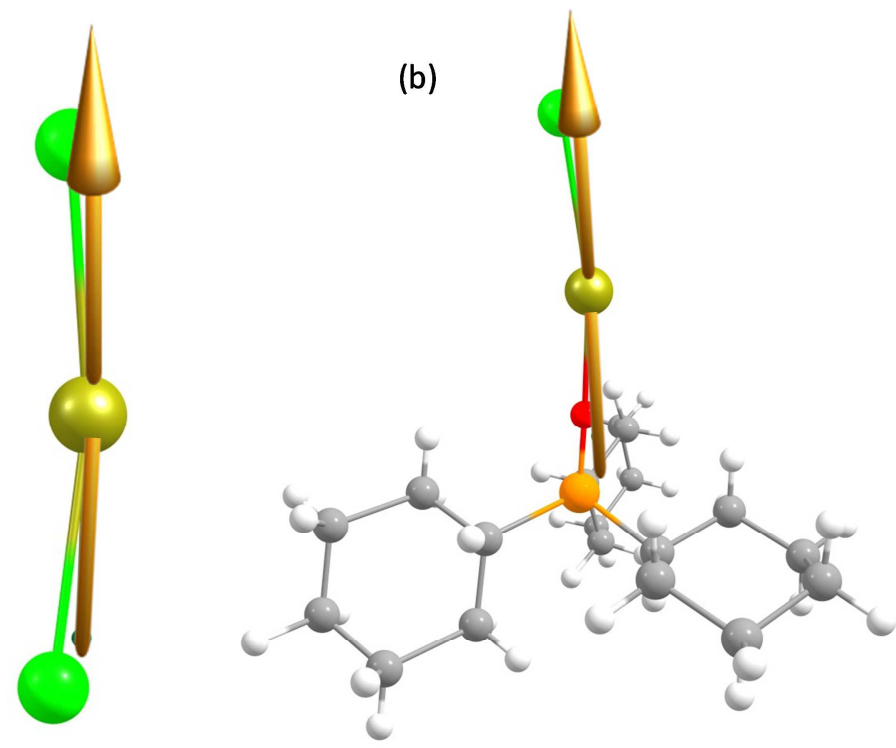

(c)

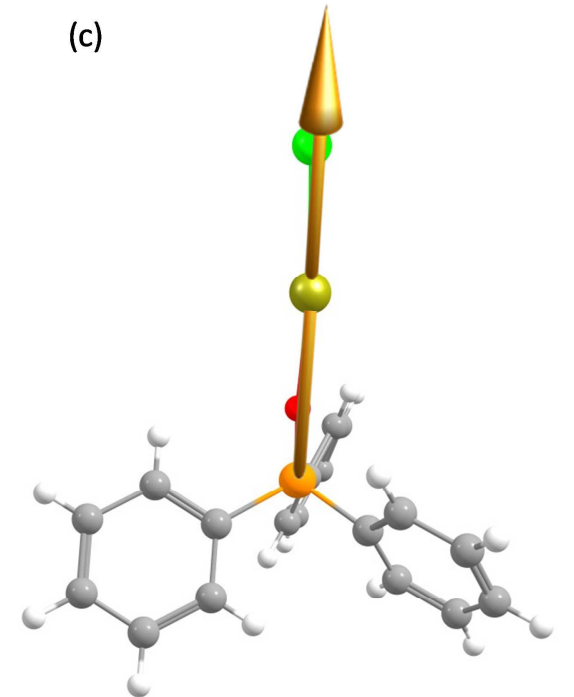

Figure S16. (a) Anisotropy axis of 3a. (b) Anisotropy axis of 4a. (c) Anisotropy axis of 6a. Colour code: Dy-greenish yellow, Cl-green, P-orange, O-red, N-blue, C-grey, H-white. 
(a)

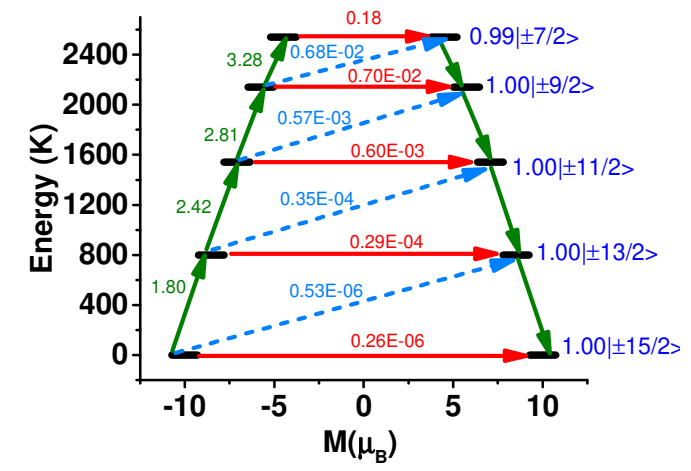

(b)

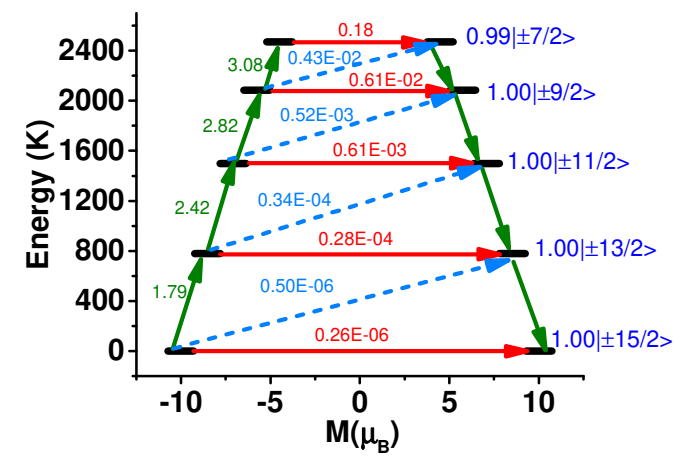

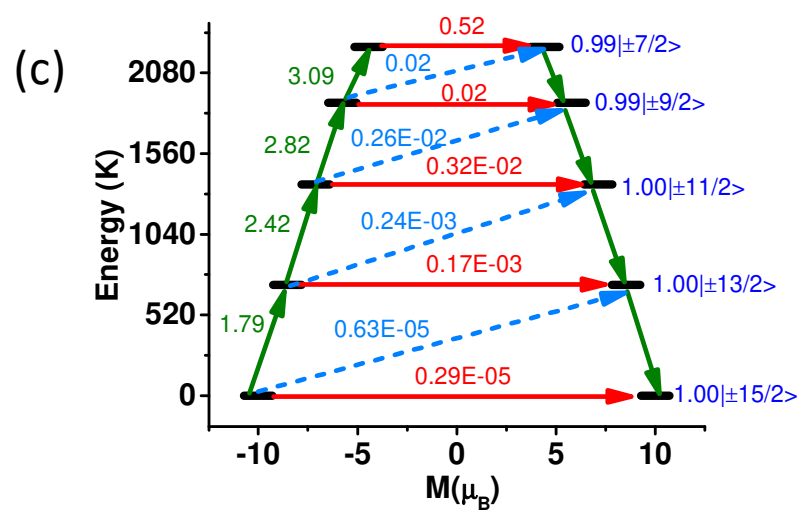

Figure S17. Mechanism of magnetic relaxation of (a) 3a (b) 4a (c) 6a. The red arrows show the QTM and TA-QTM via ground and higher excited KD respectively. The sky dotted arrows show the Orbach process for the relaxation. The green arrows show the mechanism of magnetic relaxation. The blue characters imply the $\mathrm{m}_{\mathrm{J}}$ composition of the KDs. 

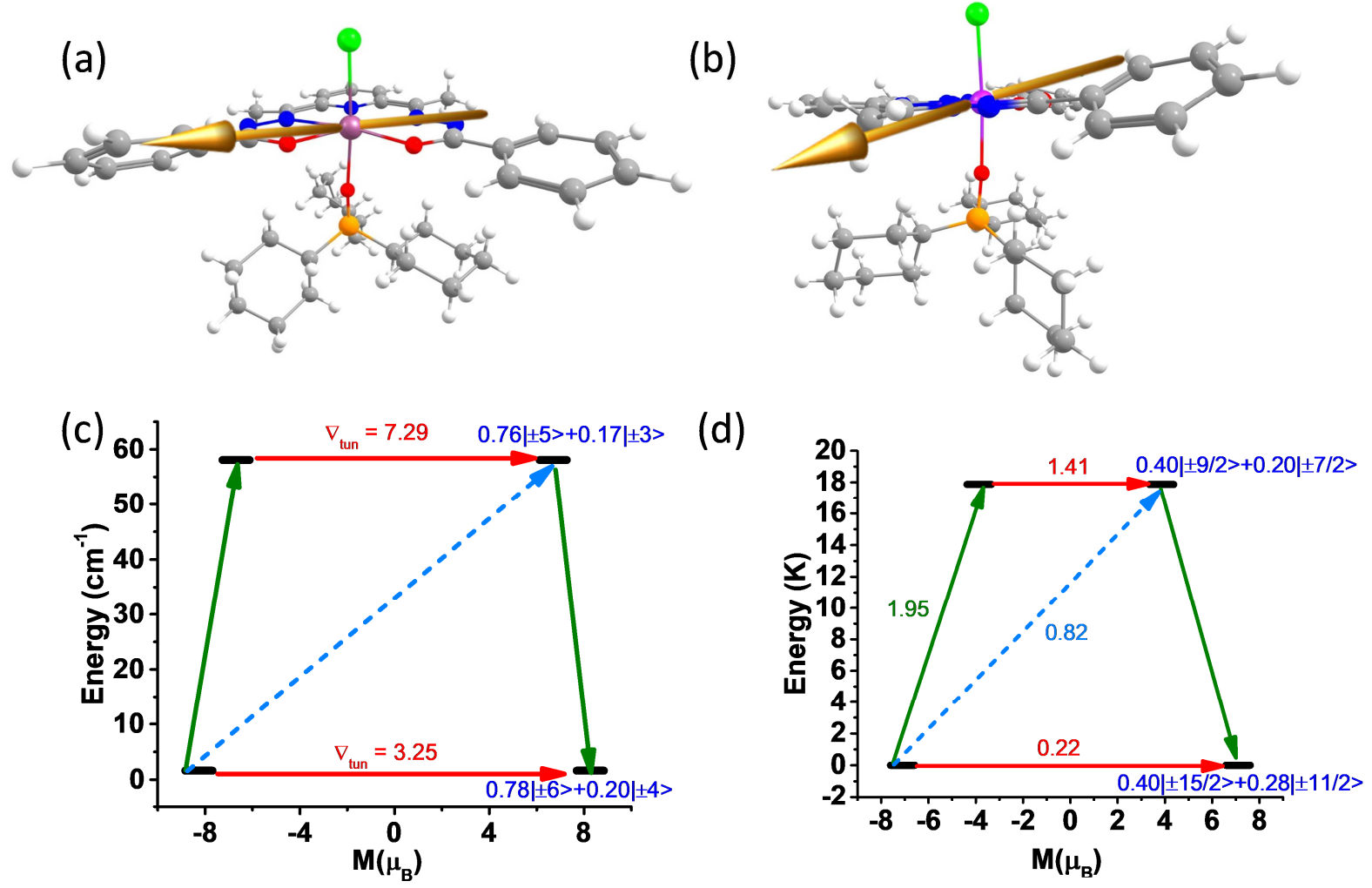

Figure S18. Computed $g_{z z}$ orientation in complex 2 and $\mathbf{5}(\mathrm{a} \& \mathrm{~b})$ and possible magnetization relaxation pathways (c \& d) respectively. Colour code: Er-Pink, Tb-Dark violet, Cl-green, Porange, O-red, N-blue, C-grey, H-white. The red dotted arrows show the QTM and TA-QTM via ground and higher excited KD respectively. The sky dotted arrows show the Orbach process for the relaxation. The green arrows show the mechanism of magnetic relaxation. The blue characters imply the $\mathrm{m}_{\mathrm{J}}$ composition of the KDs. 